\title{
Statistical estimations of the number of future ozone exceedances due to climate change in Europe
}

\author{
K. V. Varotsos, ${ }^{1}$ M. Tombrou, ${ }^{1}$ and C. Giannakopoulos ${ }^{2}$ \\ Received 5 September 2012; revised 23 April 2013; accepted 28 April 2013; published 20 June 2013.
}

[1] A statistical model to examine the potential impact of increasing future temperatures due to climate change on ozone exceedances (days with daily maximum $8 \mathrm{~h}$ average $\geq 60 \mathrm{ppb}$ ) is developed for Europe. We employ gridded observed daily maximum temperatures and hourly ozone observations from nonurban stations across Europe, together with daily maximum temperatures for 2021-2050 and 2071-2100 from three regional climate models, based on the Intergovernmental Panel on Climate Change Special Reports on Emissions Scenarios A1B scenario. A rotated principal components analysis is applied to the ozone stations yielding five principal components, which divide the study domain in five subregions. The historical ozone-temperature relationship is examined and then used to provide estimates of future ozone exceedance days under current emissions and under the assumption that this relationship will retain its main characteristics. Results suggest that increases in the upper temperature percentiles lead to statistically significant increases $(95 \%$ statistical significance level) of the ozone exceedances for both future periods. The greatest average increases depending on the particular regional climate model range from 5 to 12 extra ozone days/yr for 2021-2050 and from 16 to 25 for 2071-2100, in southeast Europe. The lowest average increases range from 0 to 2 extra ozone days/yr for 2021-2050 and from 2 to 4 for 2071-2100 and are seen in northwest Europe. The simulations with the dynamical Goddard Institute of Space Studies/GEOS-CHEM climate chemistry modeling system shows decreases instead of increases in eastern Europe, higher increases in northwest Europe, whereas for the other subregions similar results to the statistical model are obtained.

Citation: Varotsos, K. V., M. Tombrou, and C. Giannakopoulos (2013), Statistical estimations of the number of future ozone exceedances due to climate change in Europe, J. Geophys. Res. Atmos., 118, 6080-6099, doi:10.1002/jgrd.50451.

\section{Introduction}

[2] One of the major challenges in present-day atmospheric pollution studies is to provide estimates of future air-quality under the impact of climate change. Changes in climate may affect the spatial and temporal distribution of temperature, wind speed and direction, precipitation and humidity, variables well known for their impact on the gas phase chemistry, transport, and deposition of air pollutants [Jacob and Winner, 2009].

[3] The majority of the studies assesses climate change impacts on tropospheric ozone using chemical transport models coupled to climate ones in an off-line mode, for various horizontal resolutions and different present and future time slices [Jacob and Winner, 2009, and references therein; Katragkou et al., 2011, and references therein]. A complementary approach is based on present-day empirical

\footnotetext{
${ }^{1}$ Division of Environmental Physics and Meteorology, National and Kapodistrian University of Athens, Athens, Greece.

${ }^{2}$ Institute for Environmental Research and Sustainable Development, National Observatory of Athens, Athens, Greece.

Corresponding author: C. Giannakopoulos, Institute for Environmental Research and Sustainable Development, National Observatory of Athens, Athens, Greece. (cgiannak@meteo.noa.gr)

C2013. American Geophysical Union. All Rights Reserved. 2169-897X/13/10.1002/jgrd.50451
}

relations between ozone and various meteorological variables. In this context, a number of variables has been identified to be strongly correlated with ozone concentrations such as temperature, morning solar radiation, number of days since the last frontal passage, wind, humidity, and the frequency of summertime midlatitude cyclones [Ordóñez et al., 2005; Wise and Comrie, 2005; Camalier et al., 2007; Leibensperger et al., 2008]. Among these variables, temperature is found to exhibit the highest correlation with ozone concentrations [Jacob et al., 1993; Sillman and Samson, 1995; Sillman, 1999] and thus the present-day ozone-temperature relationship combined with future temperature projections can provide estimates of future ozone concentrations. Later studies used the observed ozone temperature relationship for various purposes. For example, Lin et al. [2001] analyzed the long-term trends in ozone exceedances in the U.S., considering temperature as a surrogate of meteorological conditions. More specifically, they calculated the probability distribution of the occurrence of ozone exceedance days in relation to the daily maximum temperature. Recently, D.J. Rasmussen et al. [2012] used the ozone-temperature relationship to evaluate a global climatechemical system in the eastern U.S. suggesting that if the modeling system can capture the observed relationship between ozone and temperature, it can be used for future ozone projections under climate change. 


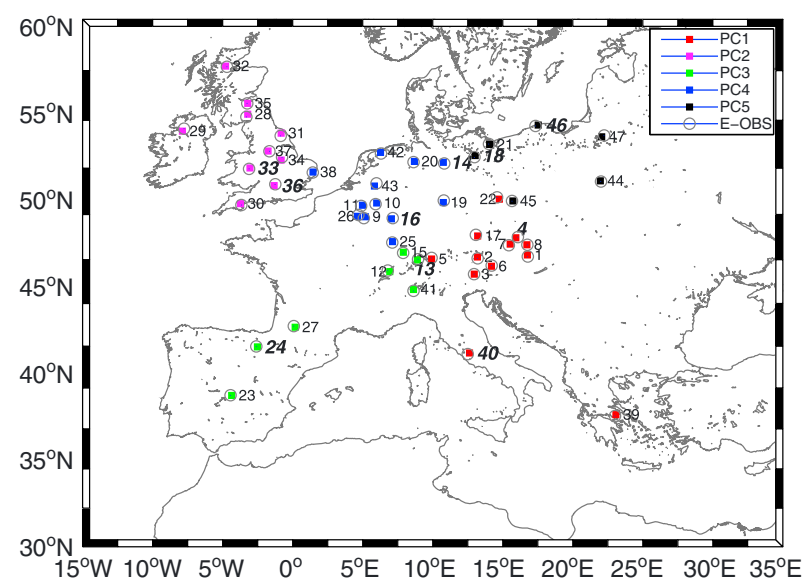

Figure 1. Locations of the ozone stations and the five homogeneous ozone subregions as obtained from PCA: southeast (red squares), northwest (magenta squares), southwest (green squares), central-north (blue squares), and northeast (black squares). Grey open circles denote the closest grid point for temperature. Subscripts denote station numbers in Table 1. The selected stations of each subregion are denoted in bold.

[4] In addition, recent regional air-quality modeling studies in Europe indicate that increased future temperatures, as projected by climate models, lead to increases in mean future ozone concentrations when anthropogenic emissions are kept constant at current levels [Langner et al., 2005; Meleux et al., 2007; Hedegaard et al., 2008; Katragkou et al., 2011; Langner et al., 2012]. Although, most of the studies demonstrate a strong relationship between ozone and temperature, it is doubtful whether statistical models based on this relationship alone can provide reliable estimates for future ozone exceedances. In particular, Steiner et al. [2010] found a near-linear relationship between daily maximum ozone concentrations and daily maximum temperature, in a specific temperature range, in the western U.S. Despite this result, they commented that using meteorological variables to extrapolate results for future air quality is insufficient and this task of research should be accomplished with the use of dynamical systems (3-D chemical models) that take into account the relationship of ozone with its precursor emissions. The reason behind this statement is because they found that saturation of peroxy acetyl nitrate decomposing to NOx and decreasing isoprene emissions at sufficiently high temperatures (above $39^{\circ} \mathrm{C}$ ) cause the near-linear relationship between ozone and temperature to break down. Bloomer et al. [2009] also found a linear relationship between hourly ozone concentrations and maximum temperatures in the eastern U.S. and they suggest that this observed relationship combined with future temperature estimates is a useful tool for determining future ozone levels. Similarly, Wise [2009] suggests that the use of statistical models could be beneficial in terms of understanding the trends of future air quality under climate warming.

[5] One of the main disadvantages of statistical models is that they are based on numerical methods that are unable to incorporate physical processes such as photochemical formation of ozone or its relationship to its precursor emissions. On the contrary, statistical models allow for a more rapid assessment of the effects of climate change on air pollutants, for a variety of climate models and scenarios, while the need for higher resolution with dynamical models, especially in areas with complex terrain or surface heterogeneity make these models computationally expensive. Most of the dynamical studies that have focused on Europe have a $50 \mathrm{~km}$ horizontal resolution [Meleux et al., 2007; Katragkou et al., 2011] and when finer resolution is applied these are confined to smaller domains [Forkel and Knoche, 2007]. Apart from the computational cost other challenges also arise with dynamical downscaling such as consistency in the physics and chemistry between the parent General Circulation Model (GCM) and regional climate model (RCM) [Jacob and Winner, 2009]. In addition, dynamical models often disagree on certain chemical mechanisms, such as the isoprene oxidization [Weaver et al., 2009], whereas the observed relationship between ozone and temperature can bypass these uncertainties.

[6] To our knowledge until now, the impact of climate change on ozone air quality under the framework of a statistical approach has seen little publication. The majority of these studies have focused on the United States [Holloway et al., 2008; Wise, 2009; Chang et al., 2010] whereas no studies exist so far for Europe. The basic assumption of these studies is that the observed relationship between ozone and meteorology remains constant in the future. For instance, Holloway et al. [2008] performed a statistical downscaling to variables from three GCMs and found ozone mixing ratios of the same magnitude or higher with those produced by dynamical studies for the area of Chicago. To conclude, we believe that results from both statistical and dynamical models could benefit our understanding on climate change impact on air quality.

[7] The objective of this study is the development and application of a statistical model to examine the potential impact of increasing future temperatures on ozone exceedance days in Europe. The motivation for this study is based on the fact that the total derivative of ozone with temperature reflects the sum of the partial derivatives of ozone with temperaturedependent physical and chemical processes [D.J. Rasmussen et al., 2012] under the assumption that their relationship will retain its main characteristics in the future. This assumption can be supported by the heat wave event of summer 2003, which impacted western Europe and invoked exceptionally high temperatures, comparable to those simulated by regional models for the latter part of the $21^{\text {st }}$ century [Beniston, 2004; Schär et al., 2004]. This episode was accompanied by unusually persistent high-ozone concentrations [Vautard et al., 2005].

[8] In our analysis, daily maximum surface temperatures obtained from a European-wide gridded observational data set and hourly ozone observations from a network of nonurban stations across Europe and daily maximum temperatures from three regional climate models are used. Moreover, the results of the statistical approach are compared with the results from a coupled climate chemistry modeling system. All results presented in this study regarding future changes are under the assumption that the current levels of emissions remain constant in the future.

[9] The remainder of the paper is divided into four sections. Section 2 describes the data and the dynamical modeling system, used in this study. Section 3 describes the general methodology followed to obtain future estimates of the ozone exceedances. The representation and discussion 
VAROTSOS ET AL.: CLIMATE CHANGE AND AIR-QUALITY

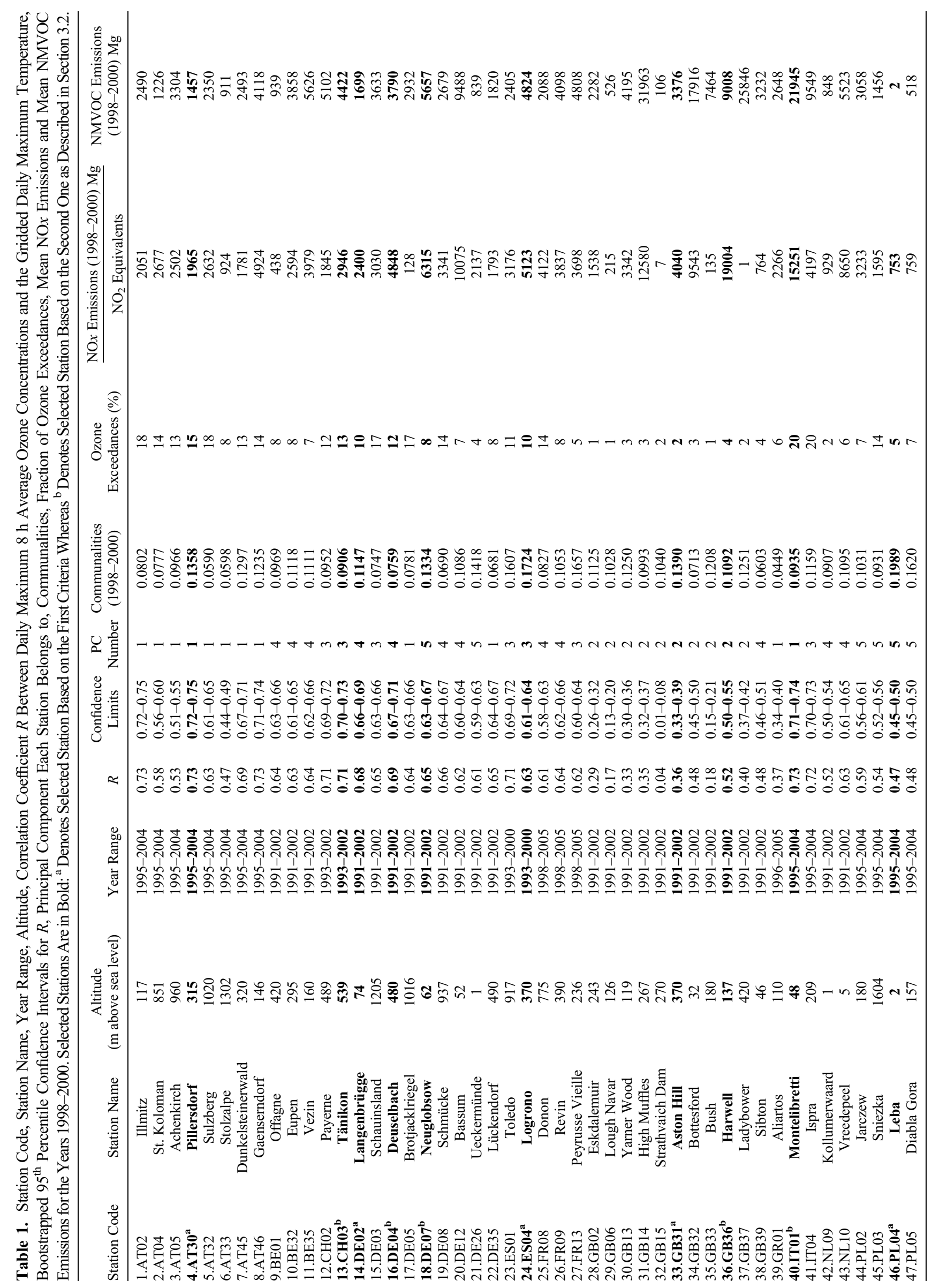


Table 2. References and Characteristics of the Daily Maximum Temperature Data Sets

\begin{tabular}{lcccc}
\hline Institute Acronym & Model Name & Driving GCM & Periods Used & Reference \\
\hline E-OBS & - & - & (1) Years corresponding to Table 1 & Haylock et al. [2008] \\
KNMI & & (2) 1961-1990 & Van Meijgaard et al. [2008] \\
MPI & RACMO2 & ECHAM5-r3 & $1961-1990 / 2021-2050 / 2071-2100$ & Jacob [2001] \\
HC & REMO & ECHAM5-r3 & $1961-1990 / 2021-2050 / 2071-2100$ & Collins et al. [2006] \\
\hline
\end{tabular}

of the results are given in section 4. Finally, conclusions are given in section 5 .

\section{Data Sources}

\subsection{Surface Ozone Observations}

[10] Hourly ozone concentrations data from 47 nonurban stations in Europe are retrieved from the European Monitoring and Evaluation Program (EMEP) database (http://www.nilu. no/projects/ccc/emepdata.html). Due to the different period of operation for each station we opt not to implement the same year range for all stations in our analysis. The locations of the analyzed stations are shown in Figure 1 (the names and the year range of the analyzed stations are summarized in Table 1). The majority of the stations with at least 10 years of observations are located in Central and Northern Europe. To extend our study domain to the southwest Europe, stations with 8 years of observations are also implemented in the analysis (e.g., stations from Spain and France). For the purposes of this study the daily maximum $8 \mathrm{~h}$ averages are used [EU Directive 2008/50/EC, 2008].

\subsection{Gridded Daily Maximum Surface Temperature and Regional Climate Models Data}

[11] Local daily maximum surface temperatures for the grid point closest to the ozone stations are obtained from the E-OBS daily gridded data set [Haylock et al., 2008] developed under the framework of the ENSEMBLES project (www.ensembles-eu.org). E-OBS is a high-resolution data set derived from statistically interpolated ground-based station data over Europe. As shown in Figure 1 the grid points chosen for our analysis are, in most of the cases, very close to where the ozone stations are located (maximum distance is less than $16 \mathrm{~km}$ ), whereas in some cases the center of the grid point coincides with the location of the ozone stations. It should be noted here that we also examined the possibility to use colocated real observations. To this aim available observed daily maximum temperature data from the European Climate Assessment data set (http://eca.knmi.nl/dailydata/index.php) [Klein Tank et al., 2002; Klok and Klein Tank, 2009], were retrieved. These data were used for the E-OBS construction. For all the ozone stations apart from one, the closest temperature station was found at a distance higher than $20 \mathrm{~km}$ where in some cases reaches $110 \mathrm{~km}$ from the location of the ozone station. Therefore, to examine ozone variations in relation to temperature, the only solution was to use the gridded temperature data. Nevertheless, in recently published works like the one from Kostopoulou et al. [2012], there has been a thorough evaluation of the ability of E-OBS to represent extremes. The paper revealed that the gridded observational data set satisfactorily reproduces temperature data and indices in most study sites, with deviations evident at high-elevation locations. In particular, the authors found that the E-OBS exhibits small deviations $\left(<2{ }^{\circ} \mathrm{C}\right)$ from the observed daily maximum temperature in most of the stations with a tendency to underestimate the observed daily maximum temperature. Higher deviations $\left(>2^{\circ} \mathrm{C}\right)$ were found in areas with low density of stations and in areas with complex terrain where interpolation usually degrades [Hofstra et al., 2009]. E-OBS also succeeds in estimating trends in extreme temperatures. Furthermore, the grid point of the E-OBS data set coincides with the grid of the RCMs we use in this study (see below). For each grid point, the daily maximum temperatures were processed for two distinct periods; the 1961-1990 period for evaluation purposes with the RCMs and the period where ozone data are available for each site (see Table 2).

[12] In addition, daily maximum temperatures from three RCMs developed at European institutes within the framework of the ENSEMBLES project (www.ensembles-eu.org) with a $25 \mathrm{~km}$ horizontal resolution, are used (Table 2). For the closest grid point to the ozone station, temperature data are extracted for three simulation periods: the 1961-1990 period to compare the models' maximum temperature with the gridded maximum temperatures and two future projections for the periods 2021-2050 and 2071-2100 to provide future ozone exceedance days using our statistical approach. The two future simulation periods of the RCMs are based on the Intergovernmental Panel on Climate Change (IPCC) Special Reports on Emissions Scenarios (SRES) A1B scenario [Nakicenovic and Swart, 2000]. It should be noted that the institute acronyms instead of the model names are used hereafter.

\subsection{GISS/GEOS-CHEM Simulations}

[13] The GEOS-CHEM chemical transport model driven by meteorological fields from the NASA/Goddard Institute for Space Studies III GCM [Rind et al., 2007] is used to assess the results of the statistical approach. The horizontal resolution is $4^{\circ} \times 5^{\circ}$ in a global scale with 23 vertical levels extending from the surface up to $0.02 \mathrm{hPa}$. For the purposes of this study two scenarios are simulated: (a) present-day climate with present day anthropogenic emissions and (b) future climate following the IPCC SRES A1B scenario and present-

Table 3. Statistics for the First 10 Unrotated Principal Components

\begin{tabular}{|c|c|c|c|c|c|c|c|c|c|c|}
\hline & PC1 & PC2 & PC3 & PC4 & PC5 & PC6 & PC7 & PC8 & PC9 & $\mathrm{PC} 10$ \\
\hline Eigenvalue & 17.48 & 5.85 & 5.23 & 3.06 & 1.66 & 1.34 & 1.16 & 1.03 & 1.00 & 0.93 \\
\hline Variance explained (\%) & 37.2 & 12.4 & 11.1 & 6.5 & 3.5 & 2.8 & 2.4 & 2.2 & 2.1 & 1.9 \\
\hline Cumulative Variance (\%) & 37.2 & 49.6 & 60.8 & 67.3 & 70.8 & 73.7 & 76.1 & 78.4 & 80.5 & 82.5 \\
\hline
\end{tabular}


Table 4. Statistics for the First Five Rotated Principal Components

\begin{tabular}{lccccc}
\hline & PC1 & PC2 & PC3 & PC4 & PC5 \\
\hline Eigenvalue & 9.08 & 7.89 & 6.72 & 5.14 & 4.45 \\
Variance explained (\%) & 19.3 & 16.8 & 14.3 & 10.9 & 9.4 \\
Cumulative Variance (\%) & 19.3 & 36.1 & 50.4 & 61.3 & 70.8 \\
\hline
\end{tabular}

day anthropogenic emissions. It should be noted that the simulations performed here follow a concept similar to those performed in Wu et al. [2008] and the reader is referred to this study for an extensive description of the GISS/GEOS-CHEM modeling system. Differences in our simulations are related to the base year anthropogenic emissions inventory (year 2000 in this study as opposed to 1999 in Wu et al. [2008]) and the area of interest (Europe as opposed to the U.S. in Wu et al. [2008]). The simulations performed here cover two 3 year time slices: 1999-2001 (2000) for the present-day climate and 2049-2051 (2050) for the future climate.

\section{Methods of Analysis}

[14] In this section the methods of analysis applied in this study are presented. First, the implementation of a rotated principal components analysis (PCA) on the daily maximum $8 \mathrm{~h}$ average ozone concentrations is described. We employ the PCA to all stations from April 1 to September 30 for all the years in common (1998-2000), to delineate regions of homogeneous ozone concentrations. Then, we examine the relationship between the daily maximum $8 \mathrm{~h}$ average ozone concentrations and daily maximum temperatures, for each station and describe the formulation of the statistical model (section 3.2). In this section, the methodology for the statistical model evaluation and for the future ozone exceedance days estimation, is provided. In section 3.3 the procedure to obtain statistical significance of the results is presented. Finally, a comparison between the statistical and the dynamical approach is presented. Apart from PCA (where only the 3 years in common were considered), for the rest of the methods the data available for all years (Table 1) have been used. (a) АT30

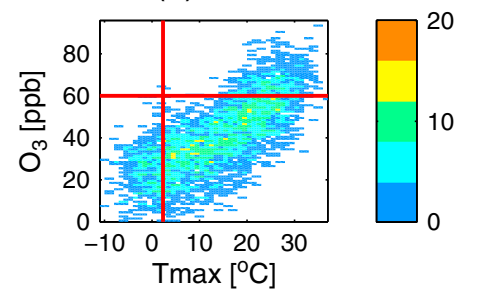

(d) GB36

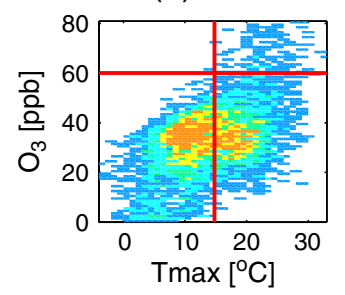

(g) DE02

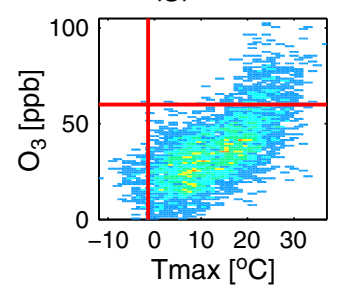

(j) DE07

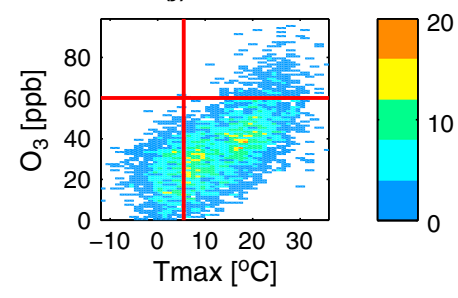

(b) IT01

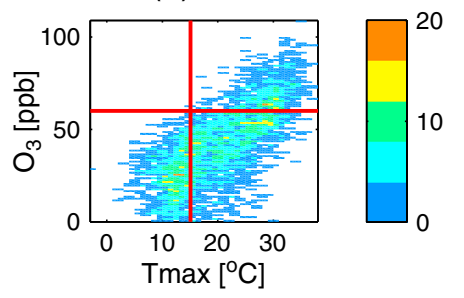

(e) ES04

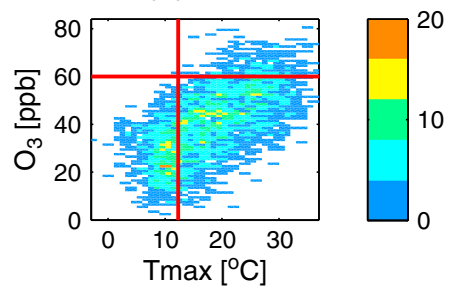

(h) DE04
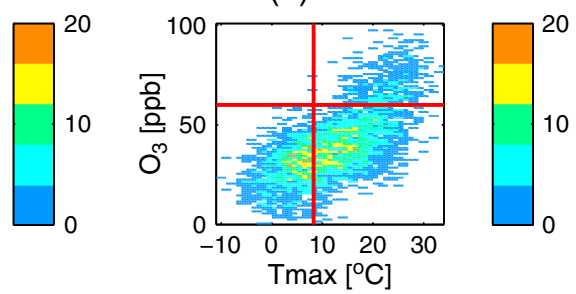

(c) GB31

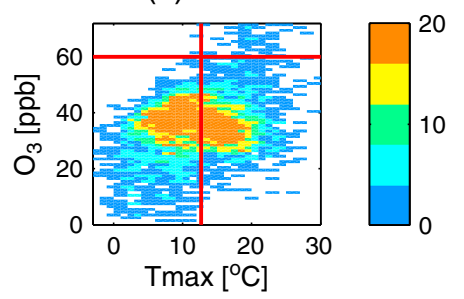

(f) $\mathrm{CHO}$

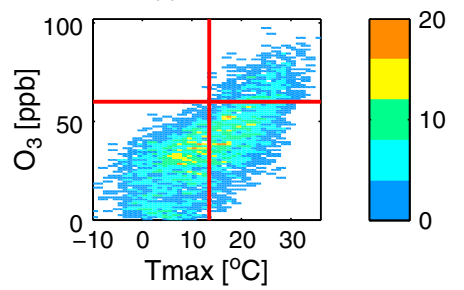

(i) PL04

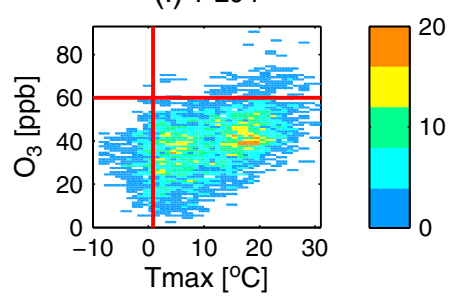

Figure 2. Ozone-temperature relationship using bins of $1 \mathrm{ppb}$ for ozone and bins of $2^{\circ}$ for temperature at the selected stations: (a) AT40 (Austria), (b) IT01 (Italy), (c) GB31 (Great Britain), (d) GB36 (Great Britain), (e) ES04 (Spain), (f) CH03 (Switzerland), (g) DE02 (Germany), (h) DE04 (Germany), (i) PL04 (Poland), (j) DE07 (Germany). Color bar indicates number of days. The red vertical line indicates the temperature at which the first ozone exceedance day is observed whereas the horizontal red line is drawn at $60 \mathrm{ppb}$. 
Table 5. List of the Subregions Identified by the Rotated PCA, Variance Explained by Each Principal Component, Mean NO $x$ and Mean Anthropogenic NMVOC Emissions for the Years 1998 to 2000, Mean Daily $T_{\max }$ and Mean Fraction of Ozone Exceedance Days, Averaged for the Stations Constituting Each Subregion

\begin{tabular}{lcccccc}
\hline PC Number & Subregion & $\begin{array}{c}\text { Variance } \\
\text { Explained (\%) }\end{array}$ & $\begin{array}{c}\text { Mean NOx Emissions NO } \\
\text { Equivalents }\left(\mathrm{Mg} / \mathrm{km}^{2}\right)\end{array}$ & $\begin{array}{c}\text { Mean NMVOC } \\
\text { Emissions }\left(\mathrm{Mg} / \mathrm{km}^{2}\right)\end{array}$ & $\begin{array}{c}\text { Mean Daily Maximum } \\
\text { Temperature }\left({ }^{\circ} \mathrm{C}\right)\end{array}$ & $\begin{array}{c}\text { Mean Ozone } \\
\text { Exceedance Days }(\%)\end{array}$ \\
\hline 1 & Southeast & 19.3 & 1.0 & 1.3 & 20.6 & 14 \\
2 & Northwest & 16.8 & 1.6 & 3.3 & 16.4 & 2 \\
3 & Southwest & 14.3 & 1.1 & 1.6 & 19 & 13 \\
4 & Central north & 10.9 & 1.2 & 1.2 & 18.9 & 8 \\
5 & Northeast & 9.4 & 0.8 & 0.6 & & 8 \\
\hline
\end{tabular}

\subsection{Rotated Principal Components Analysis}

[15] The frequency analysis performed on the ozone exceedance days (defined here as days with daily maximum $8 \mathrm{~h}$ average $\geq 60 \mathrm{ppb}$ ) [EU Directive 2008/50/EC, 2008] reveals that ozone exceedances are favored in the period from 1 April to 30 September (not shown). To identify homogeneous regions of daily maximum $8 \mathrm{~h}$ average ozone concentration in our data set, a rotated PCA is performed, using the orthogonal varimax rotation [Kaiser, 1958]. PCA is a technique widely used to establish the spatial variability of ozone in the eastern United States [Eder et al., 1993; Lehman et al., 2004; Zheng et al., 2007] and Asia [Yu and Chang, 2000] or other atmospheric constituents in Europe [Protonotariou et al., 2010]. The rotation technique is preferred when the goal of PCA is to provide physical interpretation rather than data compression [Wilks, 2011].

[16] Initially, PCA is performed on the correlation matrix of the daily maximum $8 \mathrm{~h}$ average ozone concentrations [Wilks, 2011]. To decide how many components to retain, two commonly used criteria are employed that associate the number of the extracted unrotated components with PCA products: the eigenvalues $(>1)$ [Yu and Chang, 2000] and the total variance explained (suggested value from literature 80\%) [Jolliffe, 1993]. From Table 3, it is evident that the selection of these criteria leads to eight and nine principal components, respectively. By retaining these eight or nine principal components the data set is still highly dimensional thus the purpose of PCA to reduce our data set is lost. In addition, rotating at least eight principal components leads to poorly interpretable results from a geographical point of view. In this study, geographically interpretable results are obtained by retaining the first five principal components, which approximately explain $71 \%$ of the total variance. Following Lehman et al. [2004], we could even retain the first four principal components that explain approximately $67.3 \%$ of the total variability. However, by retaining the four principal components, the stations IT01 (Italy) and GR01 (Greece) were identified in the same group with the stations of Spain (not shown). This was not consistent with the fact that the Mediterranean basin in the summer is influenced by two large, semipermanent weather systems with their natural boundary located in the area defined generally between Italy and Greece [Millán et al., 2002]. In particular, we refer to the Azores High to the west and the Asian Monsoon system to the east of the Mediterranean basin.

[17] After the rotation, the five principal components clearly define the following subregions: the southeast (SE), the northwest (NW), the southwest (SW), the central-north $(\mathrm{CN})$, and the northeast (NE) subregions (Figure 1). The statistics of the five rotated principal components are shown in Table 4. Following Zheng et al. [2007], a station belongs to a principal component (subregion) if its maximum rotated loading is found in that component. To comment on how these subregions are formed, we also examine the yearly mean NOx and nonmethane volatile organic compound (NMVOC) emissions for the closest grid point to each station, for the years 1998 to 2000 (Table 1). The emissions inventory for NOx and NMVOCs has a $0.5^{\circ} \times 0.5^{\circ}$ resolution and was obtained from the European Monitoring and Evaluation Program (EMEP) program site (http://www.ceip.at/emissiondata-webdab/emissions-as-used-in-emep-models).

\subsection{Ozone-Temperature Relationship and the Statistical Model}

[18] To examine the ozone-temperature relationship, we segregate ozone by temperature using bins of $1 \mathrm{ppb}$ for daily maximum $8 \mathrm{~h}$ average ozone concentrations and bins of $2^{\circ}$ for daily maximum temperature for all stations. Thus, the number of days occurring in each ozone-temperature bin is calculated (Figure 2). The above procedure results to an $R$ $\times C$ number of days matrix with the rows $(R)$ describing the number of ozone bins and the columns $(C)$ the temperature ones. In addition, the lowest temperature associated with the ozone exceedance days is obtained for each station and used as a threshold temperature in the subsequent analysis.

[19] The above $R \times C$ number of days matrix is transformed to a matrix with ozone probabilities for each bin of temperature. This procedure is followed for the evaluation of the statistical model and the two future projections. In particular, for the evaluation process in each station, we split the observational data set (both ozone and temperature) to two periods with the same number of years, which define the training and the evaluation period, respectively. To minimize the differences between these two periods, each period was constructed using independent yearly data; that is to say the two periods take alternate yearly data without any two data sets belonging to the same period.

[20] After obtaining the ozone probabilities (for each temperature bin) for the training period, we determine the corresponding probabilities for the evaluation period. In this procedure, the daily maximum temperatures of the evaluation period are combined with the ozone probabilities from the training period, through a uniform random generator. For example, one day of the evaluation period has a daily maximum temperature that fits to a specific temperature bin. Then, for this temperature bin, the corresponding ozone bin is calculated using the ozone-temperature probabilities from the training period. The procedure is repeated for all days of the evaluation period. Thus, when summing in each ozone bin we obtain the ozone days distribution. 


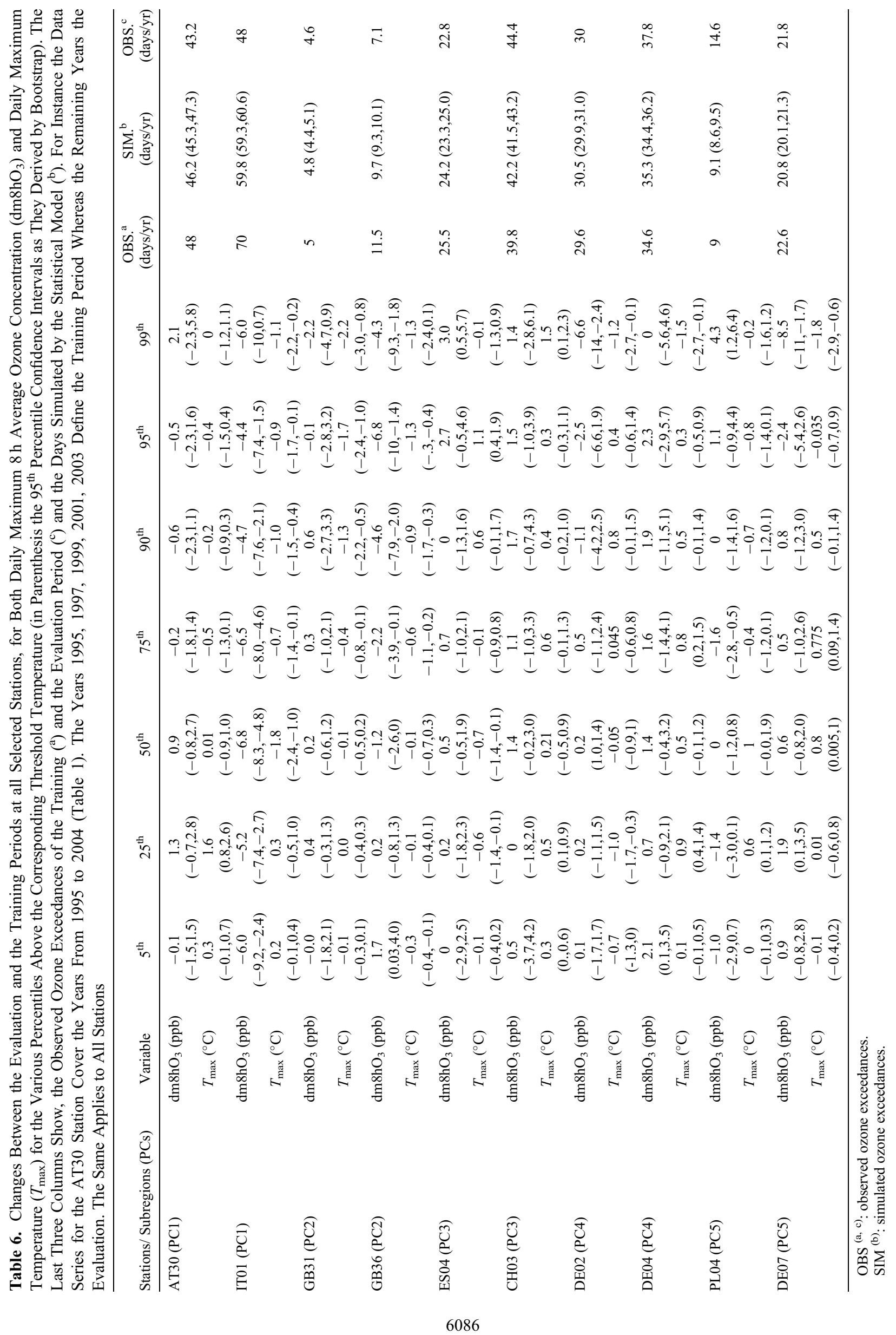


(a) South East Subregion (IT01)

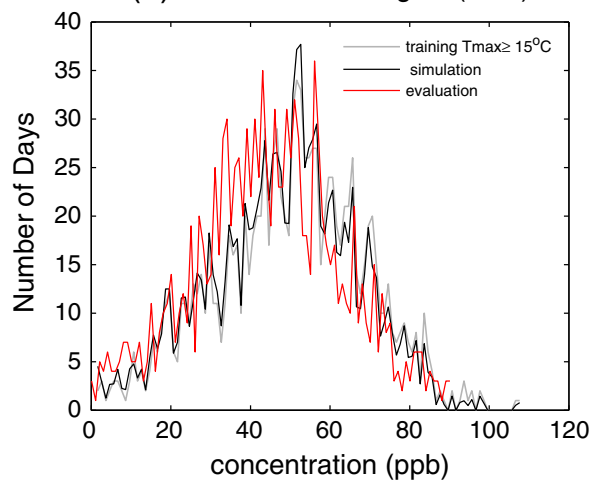

(b) North East Subregion (PL04)

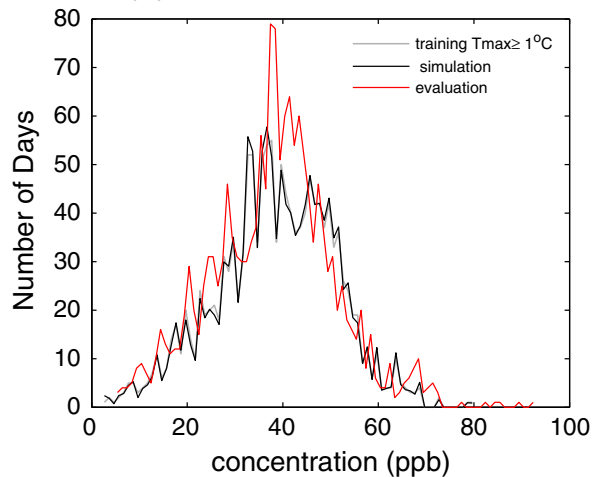

Figure 3. Evaluation of the statistical model at two selected stations in the (a) southeast and (b) northeast subregion. Red colored lines show the observed distribution of ozone at the evaluation period, black lines show the simulated by the statistical model whereas grey lines indicate the observed distribution at the training period.

[21] To get future estimates, the above probabilities are recalculated for a new training period that takes into account the whole historic period, for both ozone and temperature data. The future temperature time series (under the A1B Green House Gases (GHG) emissions scenario) are deduced by applying the delta change method [Deque, 2007; J. Rasmussen et al., 2012] to the observations. In particular, for each station, the day-to-day observations are perturbed by adding the mean monthly differences calculated from the
RCMs 30 year simulations (2021-2050 minus 1961-1990, for the first future period; 2071-2100 minus 1961-1990, for the second future period). The monthly variability is maintained since a constant monthly value is added but not the year-to-year variability. Hence, a shift of the probability distribution function to the right is expected together with a change in variance, which somewhat alters the shape of the probability distribution function (not shown). (a) South East Subregion( AT30)

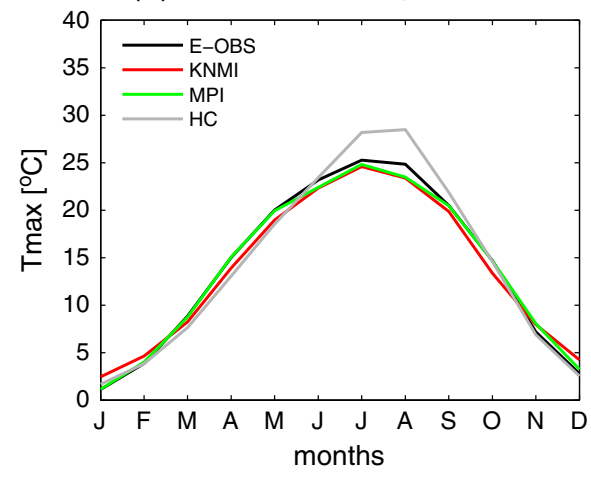

(c) North West Subregion( GB31)

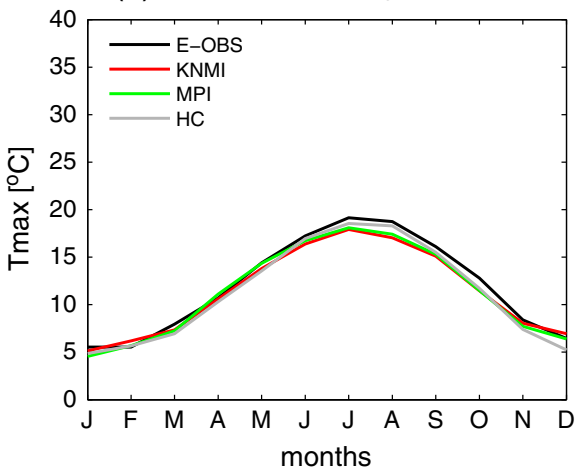

(b) South East Subregion( IT01)

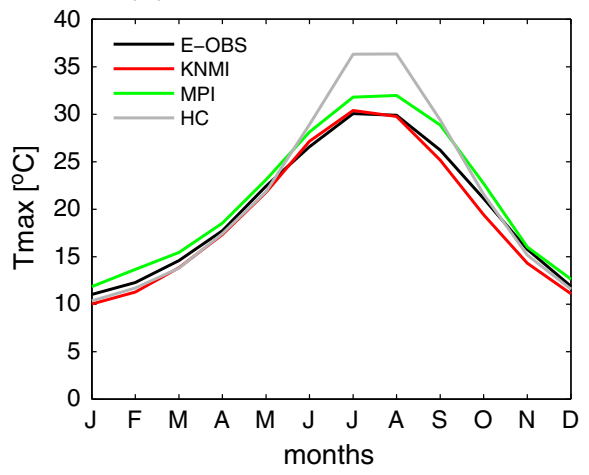

(d) North West Subregion( GB36 )

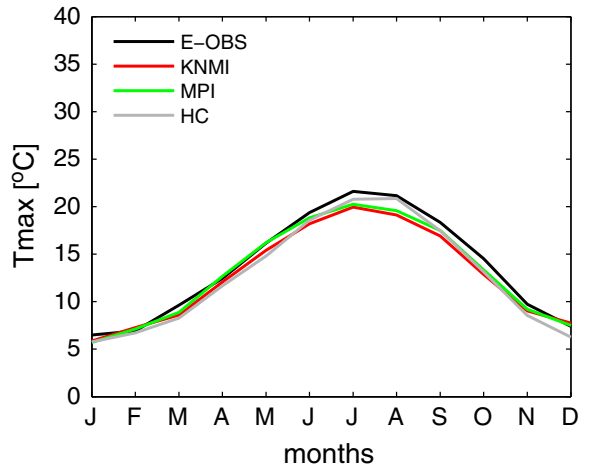

Figure 4. Annual cycle of the mean monthly maximum temperature over the period 1961-1990 for the three RCMs (KNMI, MPI, HC, Table 2) and the E-OBS at the selected stations of the southeast (a-b), the northwest (c-d), the southwest (e-f), the central north (g-h) and the northeast (i-j) subregion. 
(e) South West Subregion( ES04 )

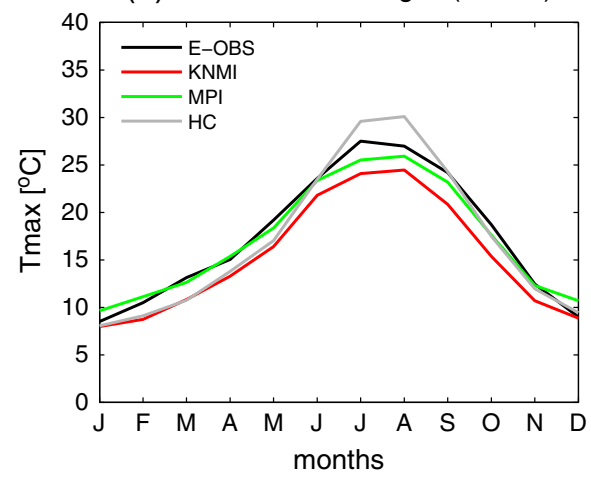

(g) Central North Subregion( DE02 )

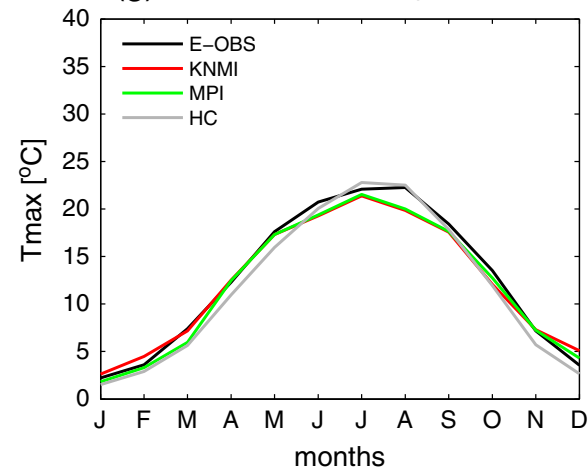

(i) North East Subregion( PL04)

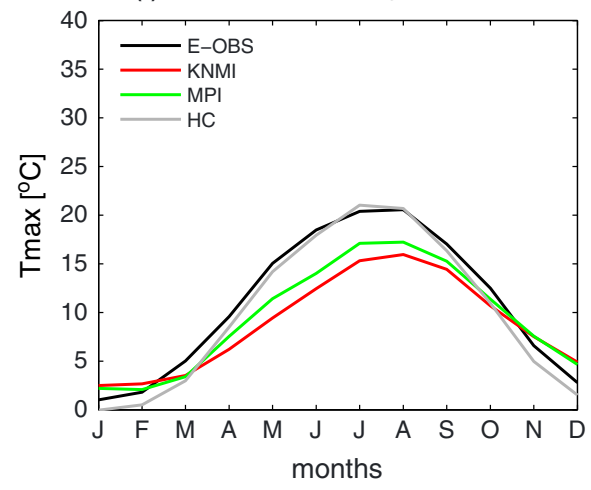

(f) South West Subregion( $\mathrm{CHO3}$ )

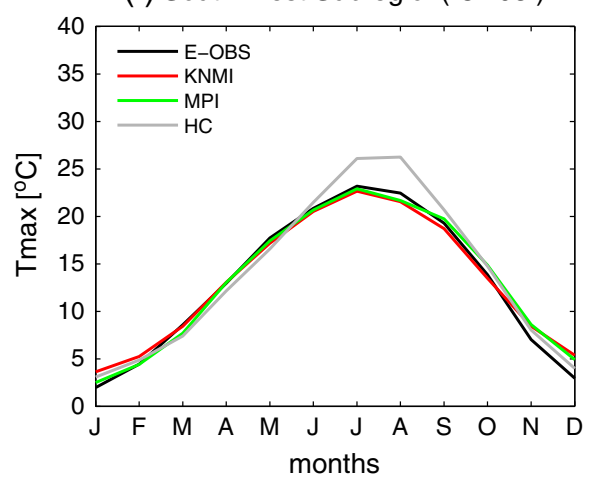

(h) Central North Subregion( DE04)

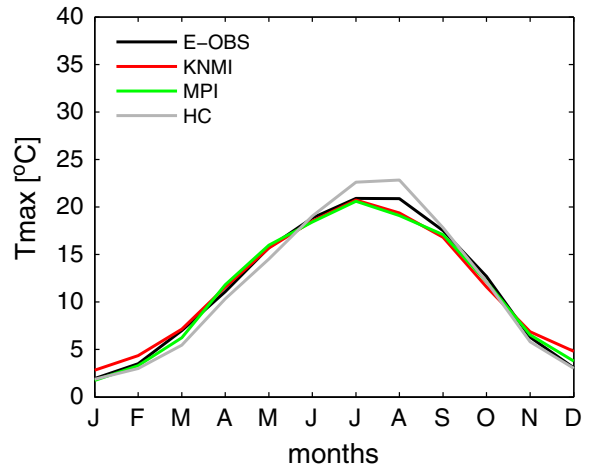

(j) North East Subregion( DE07)

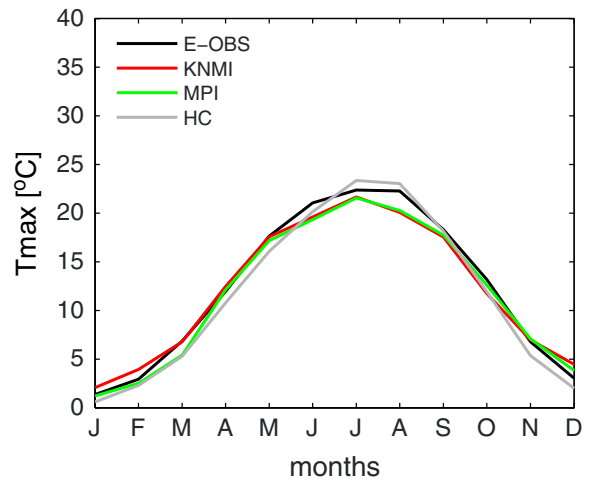

Figure 4. (continued)

[22] An in-depth analysis of the statistical model is presented for 10 stations (e.g., for two stations from each subregion, sections 4.2, 4.3, and 4.4). For the final results however, the ozone exceedance days from all the stations are considered (section 4.5). For the selection of the first station we considered the largest communality, interpreted as the proportion of variation explained by the five retained principal components [Eder et al., 1993; Zheng et al., 2007]. For the second station we took into account the availability of ozone data (at least 10 years of observations), the high positive correlation coefficient of maximum $8 \mathrm{~h}$ average ozone concentration with daily maximum temperature and, where possible, a wider geographical coverage of the subregion. When both criteria are satisfied by one station, the station with the second highest performance is also selected (Table 1).

\subsection{Statistical Significance of the Results}

[23] The statistical significance of the results is assessed both for the simulated ozone exceedances (section 4.3) and for their changes in relation to the observed ones (4.5), using the bootstrap $95^{\text {th }}$ percentile confidence intervals [Efron, 1987; DiCiccio, 1996]. In particular, the methodology described in the previous paragraphs is repeated 30 times, which is adequate to calculate the $95^{\text {th }}$ percentile confidence intervals with bootstrap [Mudelsee and Alkio, 2007]. In particular, the sample of the 30 values is randomly sampled with replacement 10,000 times (bootstrap) to obtain a mean value, each time. Consequently, the $95^{\text {th }}$ confidence intervals are calculated from the resulting series. When simulated ozone exceedances are discussed (section 4.3), their number is calculated by applying the stochastic model 30 times and then their 
(a) South East Subregion( AT30)

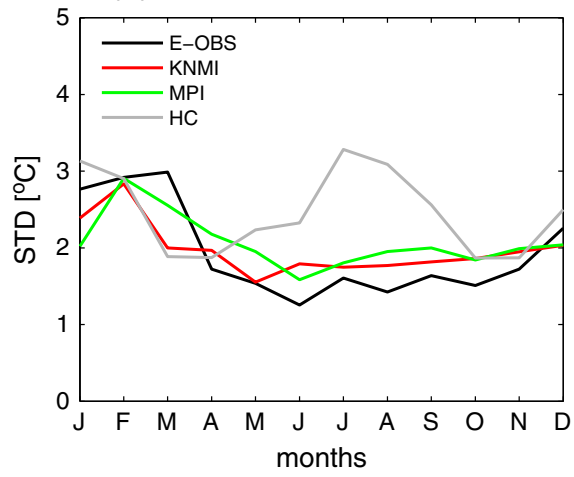

(c) North West Subregion( GB31)

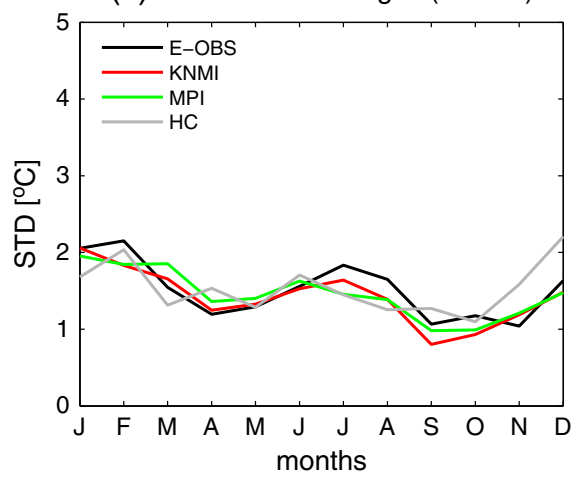

(b) South East Subregion( IT01)

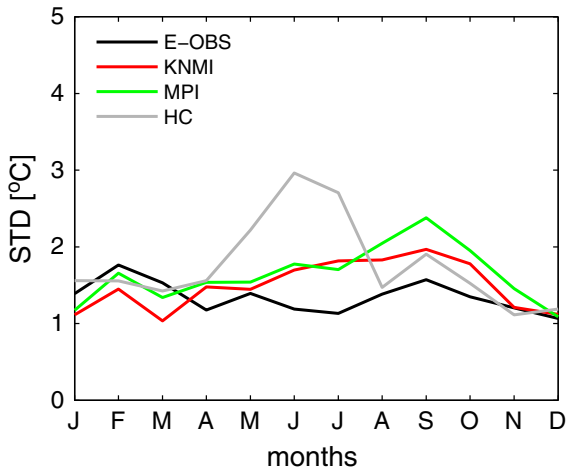

(d) North West Subregion( GB36 )

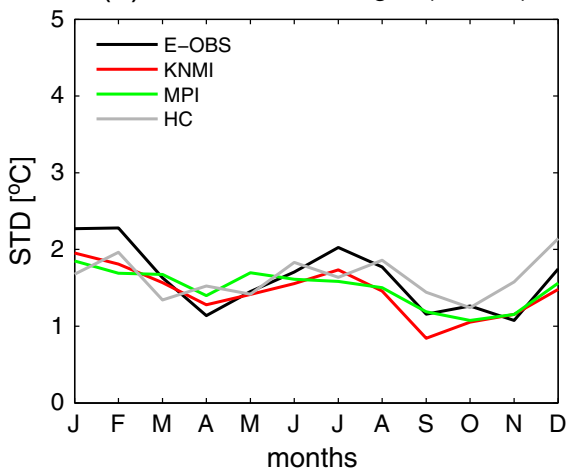

Figure 5. Interannual variability (standard deviation, (STD)) of the monthly mean maximum temperature over the period 1961-1990 for the three RCMs (KNMI, MPI, HC, Table 2) and the E-OBS at the selected stations of the southeast (a-b), the northwest (c-d), the southwest (e-f), the central north (g-h) and the northeast (i-j) subregion.

mean value is obtained and compared to the observed one. Accordingly, when changes are discussed (sections 4.3 and 4.5) the comparison is performed with the differences calculated for 30 times between the simulated and the observed ozone exceedances. According to theory, a difference is statistically significant when the confidence interval does not include zero [McCluskey and Lalkhen, 2007]. In a similar way, the bootstrap $95^{\text {th }}$ percentile confidence intervals are calculated for the changes of the various percentiles of the daily maximum $8 \mathrm{~h}$ average ozone concentration (section 4.3) and for the daily maximum temperature distributions (sections 4.3 and 4.5).

[24] Finally, the results of the statistical approach are examined against those simulated by the GISS/GEOS-CHEM dynamical system. To this aim, the first sigma level of the GISS/GEOS-CHEM extending from surface up to $99 \mathrm{~m}$ was selected. A limiting factor to be taken into consideration is the poor representation of mountainous areas due to the coarse resolution of the dynamical model [Vautard et al., 2009]. However, in our data set only 5 out of the 47 stations are located in altitudes above $1000 \mathrm{~m}$ (stations AT32, AT33, DE03, DE05, and PL03, Table 1).

\section{Results}

\subsection{PCA Results}

[25] The subregions identified by the rotated PCA, with their variances, the mean fraction of ozone exceedance days, the mean NOx and NMVOC emissions and the mean daily $T_{\max }$ (averaged for the stations constituting each subregion), are presented in Table 5. The first rotated principal component, PC1, which explains $19.3 \%$ of the total variance, is the dominant component and accumulates stations in the eastern and the southeastern areas of the study region (Figure 1). Examination of Table 1 reveals that the majority of the stations belonging to PC1 exhibit high fractions of the ozone exceedance days $(>13 \%)$. On the contrary, the second rotated principal component (PC2 explaining $16.8 \%$ of the total variance) encompasses the majority of the stations located in Great Britain (northwest subregion) with the lowest fractions of ozone exceedance days (1 to $4 \%$ ). Stations located in similar latitudes with those in PC1 but further west define the third rotated principal component (southwest subregion) explaining $14.3 \%$ of the total variance and having comparable fractions of ozone exceedance days to those in PC1 (the maximum reaching 20\%). Finally, the fourth and the fifth rotated principal components, which explain lower percentages of the total variance, $10.9 \%$ and $9.4 \%$, respectively, accumulate stations in the central and northeastern parts of the study region. In general, the fractions of ozone exceedance days in PC4 and PC5 are higher than those belonging in $\mathrm{PC} 2$ and lower than those belonging in PC1 and PC3. From Table 5 and Figure 1 it is evident that the lowest (PC2) and modest (PC4 and PC5) mean fractions of ozone exceedances are accompanied with the lowest and modest mean daily maximum temperatures, respectively. All three subregions (northwest, central-north, and 
(e) South West Subregion( ES04 )

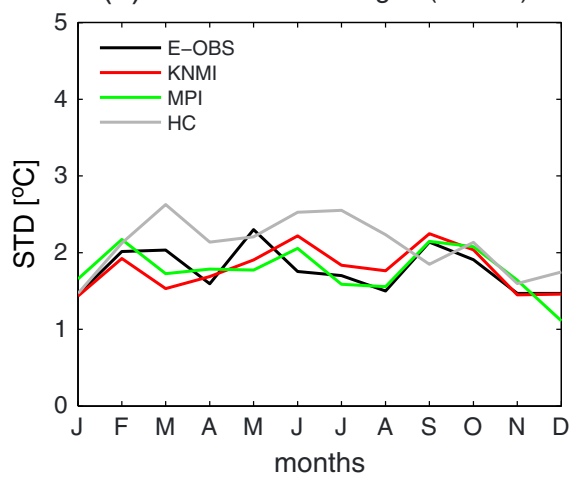

(g) Central North Subregion( DE02 )

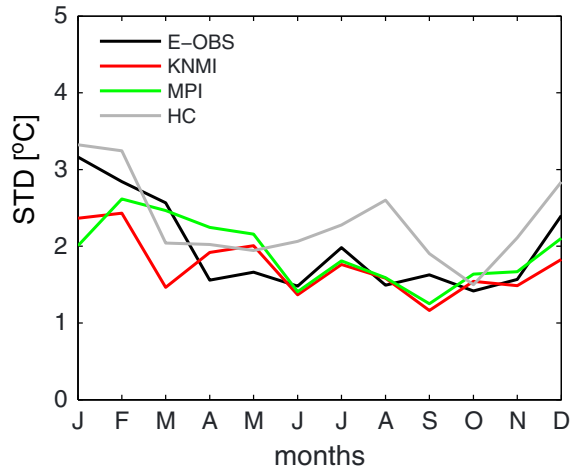

(i) North East Subregion( PL04 )

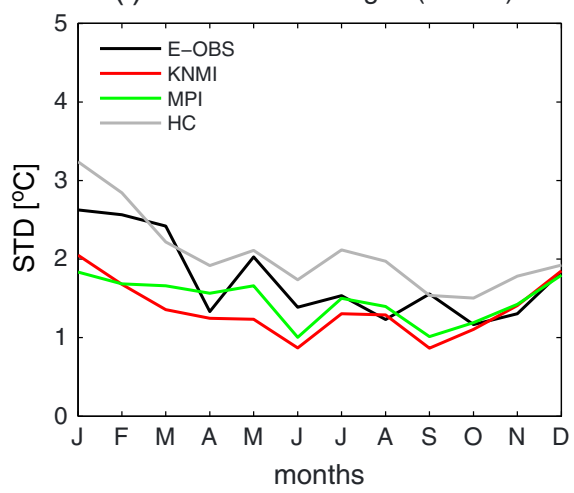

(f) South West Subregion( $\mathrm{CHO}$ )

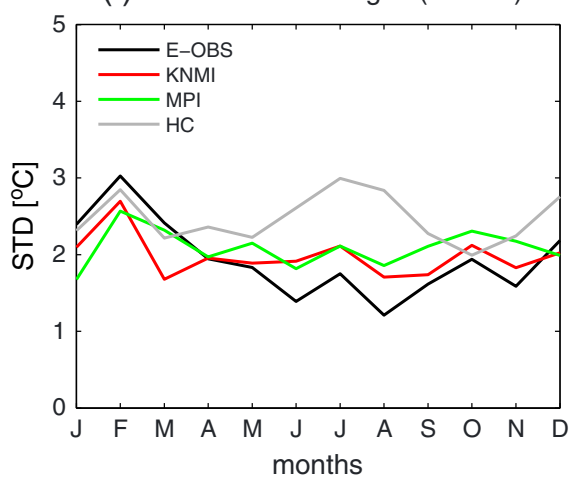

(h) Central North Subregion( DE04 )

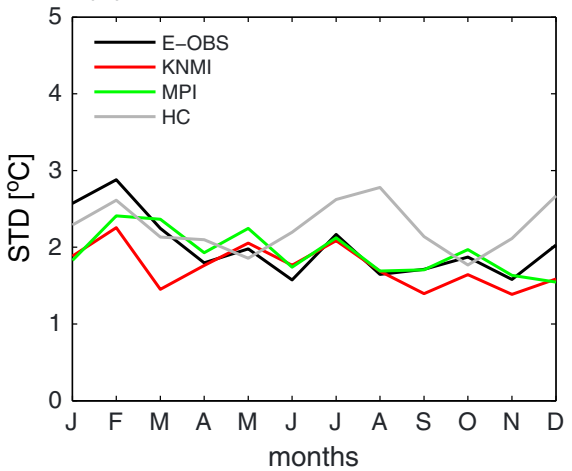

(j) North East Subregion( DE07 )

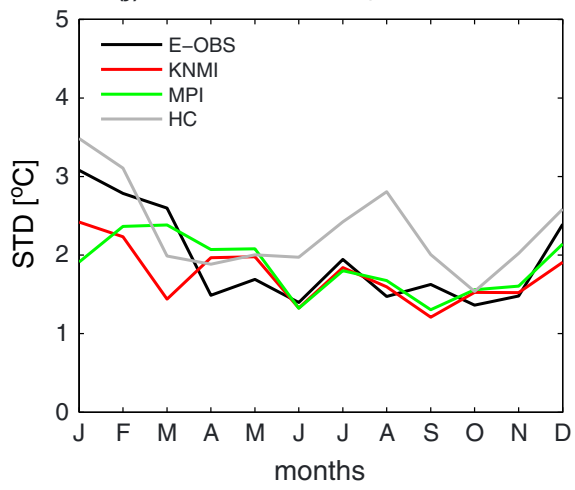

Figure 5. (continued)

northeast) are located in similar latitudes. Lower temperatures indicate lower levels of sunlight, which lead to less intense net photochemical ozone production. Moreover, the highest ozone precursor emissions in $\mathrm{PC} 2$ contribute to the lowest mean fraction of ozone exceedances. On the contrary, at the stations in lower latitudes (PC1 and PC3), the highest mean fractions of ozone exceedances occur under the highest mean daily maximum temperatures receiving similar levels of NOx and NMVOCs, much smaller than those in PC2.

\subsection{Ozone-Temperature Relationship Results}

[26] Analysis of Figure 2 in combination with Table 1 reveals that the $\mathrm{O}_{3}$ response to temperature is closely associated both with station location and with local emissions. In general, $\mathrm{O}_{3}$ increases with temperature with the highest correlations between the two variables evident at the stations located at the southern latitudes (PC1 and PC3) and the lowest ones at the stations of PC2. The lowest temperatures associated with ozone exceedances strongly depend on latitude and vary from $-1{ }^{\circ} \mathrm{C}$ in the northern part of the central north subregion (DE02, Figure $2 \mathrm{~g}$ ) to $15^{\circ} \mathrm{C}$ in the southern part of the southeast subregion (IT01, Figure 2b). Another feature arising from Figure 2 is the high number of days with concentrations around 40 to $50 \mathrm{ppb}$ occurring at very low temperatures (winter) especially at the selected stations of PC2, PC4, and PC5 regions (Figures $2 \mathrm{c}-2 \mathrm{~d}$ and $2 \mathrm{~g}-2 \mathrm{j}$ ). This behavior may reflect the reduction in the titration of $\mathrm{O}_{3}$ by $\mathrm{NO}$ due to $\mathrm{NO} x$ emission reduction policy, being in effect in Europe after the 1990s [Jonson et al., 2006]. More specifically, Jonson et al. [2006] found that the emission reductions occurred in Europe after the 1990s led to an 
(a) Observed Ozone exceedances

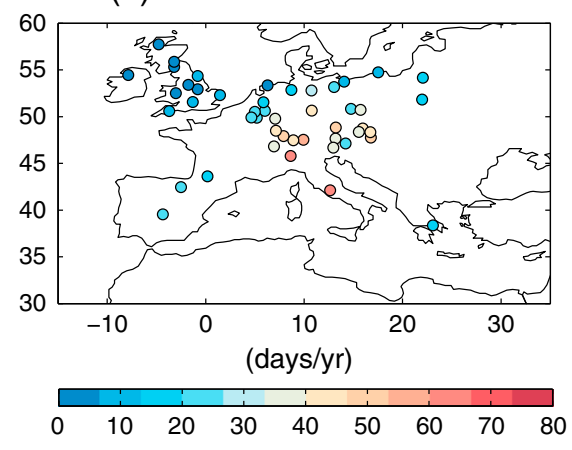

(c) MPI Ozone exceedances [2021_2050 - observed]

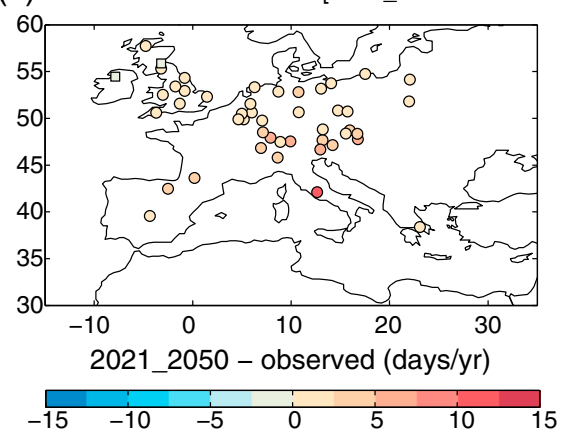

(b) KNMI Ozone exceedances [2021_2050 - observed]

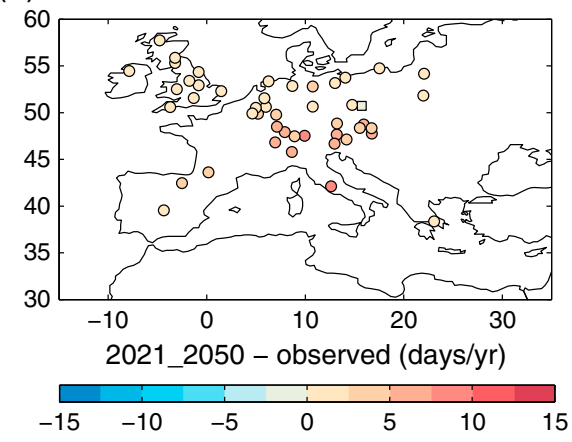

(d) HC Ozone exceedances [2021_2050 - observed]

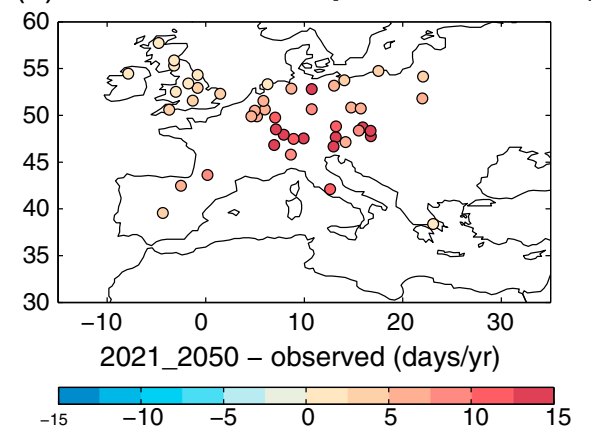

Figure 6. Observed ozone exceedance days averaged for each station over the years indicated in Table 1 and the differences between the days simulated for each RCM (KNMI, MPI, HC, Table 2) and the observed for the period 2021-2050. Filled squares indicate no statistically significant differences whereas filled circles indicate statistically significant ones. For convenience in the comparison with the results of GISS-GEOS/CHEM the same range of values as in Figure 11 has been used.

increase in ozone in winter and a decrease in ozone pollution episodes.

\subsection{Statistical Model Evaluation}

[27] In this section, the results of the statistical model for the ozone exceedance days are compared against the observed of the evaluation period. Moreover, changes in ozone and temperature, between the training and the evaluation periods, are also examined. Thus, the $5^{\text {th }}, 25^{\text {th }}, 50^{\text {th }}, 75^{\text {th }}, 90^{\text {th }}$, $95^{\text {th }}$, and the $99^{\text {th }}$ percentiles of the daily maximum $8 \mathrm{~h}$ average ozone and temperature, above the threshold temperature, are calculated for each station, (Table 6). All results presented here are tested for statistical significance with the bootstrap $95^{\text {th }}$ percentile confidence intervals.

[28] Overall the statistical model overestimates the observed ozone exceedances of the evaluation period in four stations and underestimates in other four (Table 6). No statistically significant changes are found in the remaining two stations. In addition, it is evident that the most pronounced differences between the simulated and the observed ozone exceedances are evident at the stations GB36 (37\%) and PL04 (38\%). In particular, the statistical model overestimates relative to the observations at the GB36 (about 2.5 days/yr) station, whereas it underestimates at the PL04 (about 5.5 days/yr). In terms of days/yr, the highest overestimation is evident at the IT01 station (about 12 days/yr, (25\%)) while for the remaining stations, the absolute differences vary from 0 to 3 days/yr.
[29] Figure 3 shows the observed ozone days distributions for the training (grey) and the evaluation (red) periods together with those from the statistical model (black) for the stations with the highest differences (IT01, PL04). The simulated distributions follow the shape pattern of the training periods and lie between the training and the evaluation ones. From Table 6 and Figure $3 a$ it is evident that at the IT01 station, statistically significant decreases occur in the average and upper percentiles for both ozone (up to $6.8 \mathrm{ppb}$ ) and temperature (up to $1.8^{\circ} \mathrm{C}$ ) during the evaluation period. It is worth mentioning that in the heat wave episode in the summer of 2003 - a year included in the training period - the threshold value of ozone exceedances was frequently violated [EEA, 2003]. This explains the differences in the ozone exceedances between the training and the evaluation period. Therefore, the lower temperature, during the evaluation period forces the statistical model to simulate lower ozone exceedances than the training period but still overestimating the ones of the evaluation period. On the contrary, at the PL04 station, no statistically significant changes are evident for temperature especially at the average and upper percentiles. Therefore, due to the insignificant changes in temperature, the statistical model calculates roughly the same number of ozone exceedances (about 9 days/yr) as in the training period, while it underestimates the observed ozone exceedances in the evaluation period (Table 6 and Figure 3b). Moreover, from this station, it is evident that changes in ozone and hence in ozone exceedances cannot be solely explained by the changes in temperature, therefore other factors such as wind speed and humidity should be 
(a) E-OBS 90th percentile $\operatorname{Tmax}\left({ }^{\circ} \mathrm{C}\right)$

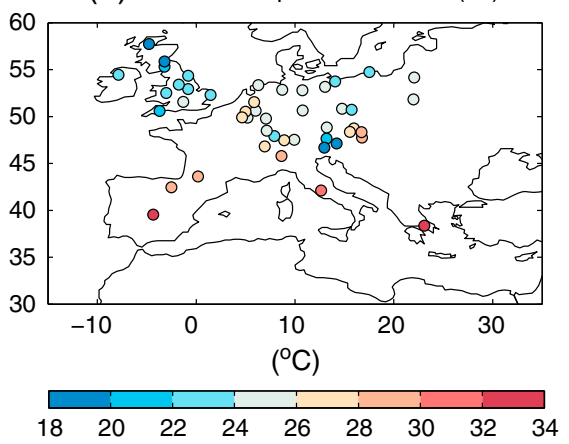

(c) MPI 90th percentile Tmax [2021_2050 - E-OBS]

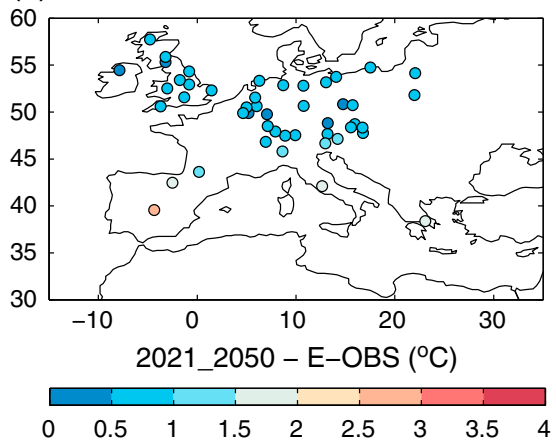

(b) KNMI 90th percentile Tmax [2021_2050 - E-OBS]

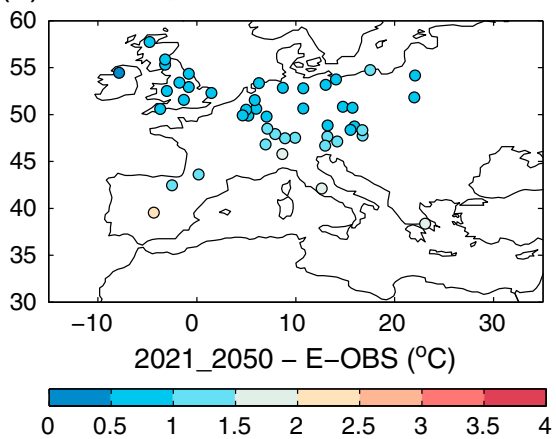

(d) HC 90th percentile Tmax [2021_2050 - E-OBS]

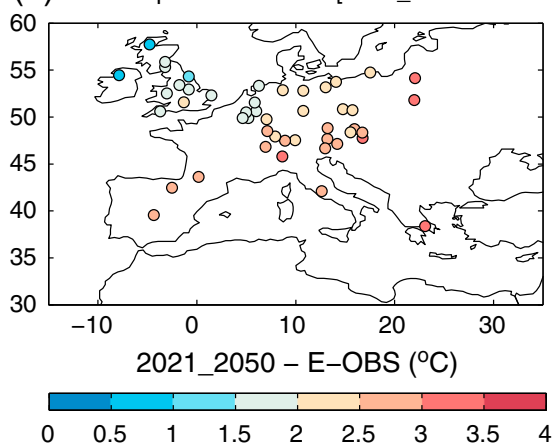

Figure 7. The $90^{\text {th }}$ temperature percentile for the E-OBS for all stations and the differences between the perturbed temperatures of each RCM (KNMI, MPI, HC, Table 2) and the E-OBS for the period 2021-2050. All changes are found statistically significant. For convenience in the comparison with the results of GISS-GEOS/CHEM the same range of values as in Figure 12 has been used.

considered. However, observations of these variables are not easily available on high temporal and spatial scales and thus the domain of study would be limited to certain parts of Europe.

[30] We also performed a sensitivity test using bins of $1^{\circ} \mathrm{C}$ for temperatures in the evaluation of the statistical model and examined the differences in the ozone exceedances using $2^{\circ} \mathrm{C}$ and $1^{\circ} \mathrm{C}$ temperature bins. The results indicate that in half of the selected stations (GB31, ES04, CH03, DE02, and DE04) there are no statistically significant differences between the two approaches while for the rest of the stations the maximum absolute difference is about 1 day/yr (corresponding to about $5 \%$ of the total number of ozone exceedances at station DE07, Table 6).

\subsection{Regional Climate Models Evaluation}

[31] Before projecting the maximum $8 \mathrm{~h}$ average ozone to the future, it is important to compare the RCMs data with the gridded data. The annual cycle of mean monthly maximum temperatures over the period 1961-1990 was calculated for each selected station to illustrate differences in the seasonal variability between the modeled (from RCMs) and the gridded data set (Figure 4).

[32] The RCMs capture quite well the seasonal cycle of the maximum temperature and the peak is observed either in July or in August at the majority of the selected stations. The average root-mean-square error (RMSE) varies from about $1^{\circ} \mathrm{C}$ for the Max Planck Institute (MPI) model to about $1.4^{\circ} \mathrm{C}$ for the Koninklijk Nederlands Meteorologisch
Instituut (KNMI) model. The highest average RMSE for KNMI is attributed to the higher RMSE evident in two stations ES04 $\left(2.4^{\circ} \mathrm{C}\right.$, Figure $\left.4 \mathrm{e}\right)$ and PL04 $\left(3.2^{\circ} \mathrm{C}\right.$, Figure $\left.4 \mathrm{i}\right)$ whereas for the rest of the stations RMSE varies from 0.8 (GB33, Figure $4 \mathrm{c}$ ) to $1.1^{\circ} \mathrm{C}$ (DE02, Figure $4 \mathrm{~g}$ ). For MPI, the RMSE varies from about 0.5 (AT30, Figure $4 \mathrm{a}$ ) to $2.4^{\circ} \mathrm{C}$ (PL04, Figure 4i) whereas for the Hadley Center (HC) model from 0.7 (GB33, Figure 4c) to $2.4^{\circ} \mathrm{C}$ (IT01, Figure 4b). In Figure 5 the interannual variability of mean monthly temperatures, for the E-OBS and the three models is presented. In general the E-OBS show relatively little seasonal cycle in interannual variability of monthly mean temperatures but higher than the RCMs. The KNMI and the MPI models however, show more variability in winter than in summer and less variability than the gridded data in summer for the selected stations of PC1 (Figures 5a-5b) and PC3 (Figures 5e-5f) whereas more variability in summer than in winter is evident for the $\mathrm{HC}$ at the same stations. It should be noted here that the summer peaks for the HC in these stations coincide with the peaks observed in the seasonal cycle of temperature (Figures $4 a-4 b$, $4 \mathrm{e}-4 \mathrm{f})$. For the stations of the PC4 and PC5 subregions (Figures $5 \mathrm{~g}-5 \mathrm{~h}$ and $5 \mathrm{i}-5 \mathrm{j}$ ) all models show more variability in summer than in winter with KNMI and MPI indicating similar variability to the observed in summer. Finally, all models perform better at the stations of PC2 (Figures 5c-5d).

\subsection{Future Ozone Exceedances Estimation}

[33] In Figures 6 and 8 the changes in the ozone exceedance days, between the observed (averaged for each station over the 
(a) Observed Ozone exceedances

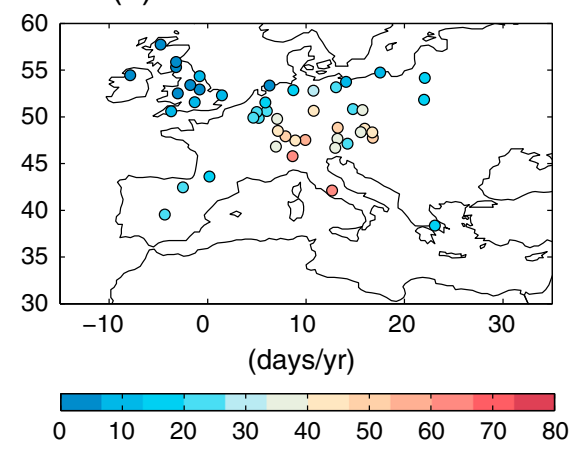

(c) MPI Ozone exceedances [2071_2100 - observed]

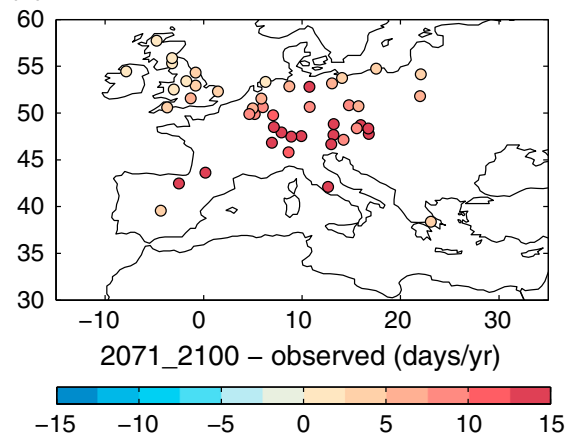

(b) KNMI Ozone exceedances [2071_2100 - observed]

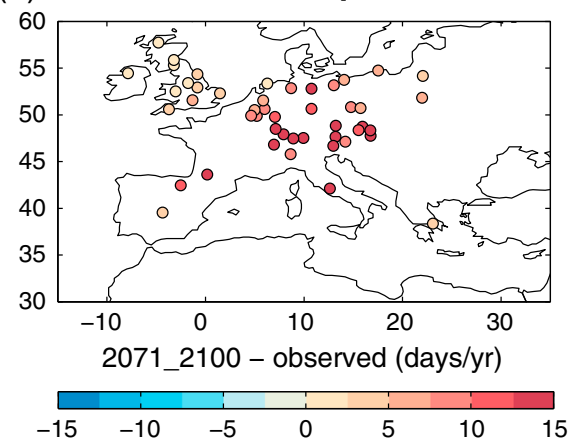

(d) HC Ozone exceedances [2071_2100 - observed]

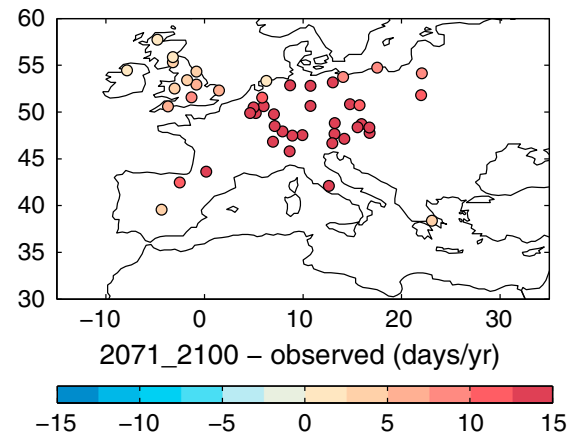

Figure 8. Observed ozone exceedance days averaged for each station over the years indicated in Table 1 as well as the differences between the days simulated for each RCM (KNMI, MPI, HC, Table 2) and the observed for the period 2071-2100. Filled squares indicate no statistically significant differences whereas filled circles indicate statistically significant ones. For convenience in the comparison with the results of GISS-GEOS/CHEM the same range of values as in Figure 11 has been used.

years shown in Table 1) and those from the statistical model for both future periods, are presented for all stations. In addition, changes in the upper extreme of temperature $\left(90^{\text {th }}\right.$ percentile) are shown in Figures 7 and 9. The changes in ozone exceedances and temperature are examined for statistical significance using the bootstrap procedure. In particular, there are statistically significant increases of the ozone exceedances for the majority of the stations, for both future periods and for all RCM models when compared to the observed ones (Figures 6 and 8). Only at one station for KNMI and two for
MPI, no statistically significant changes are found at the first future period (Figures $6 \mathrm{~b}$ and $6 \mathrm{c}$, filled squares). The average changes of both ozone exceedance days and upper extremes of temperatures for each subregion (PC) are shown in Table 7. It is evident that higher increases, in terms of days/yr, correspond to the stations of PC1 and PC3, moderate for those belonging to PC4 and lower for those of PC2 and PC5. This distribution applies for all models and for both future periods. Regarding the models, the KNMI and the MPI show similar results probably due to the same parent GCM (Table 2), whereas the higher

Table 7. Changes in the Ozone Exceedance Days Per Year as Well in the $90^{\text {th }}$ Percentile of Temperature Averaged for the Stations Belonging to Each Subregion (PC)

\begin{tabular}{|c|c|c|c|c|c|c|c|c|c|c|}
\hline \multirow{2}{*}{$\begin{array}{l}\text { Model/ } \\
\text { Subregion }\end{array}$} & \multicolumn{2}{|c|}{ PC1 } & \multicolumn{2}{|c|}{$\mathrm{PC} 2$} & \multicolumn{2}{|c|}{ PC3 } & \multicolumn{2}{|c|}{ PC4 } & \multicolumn{2}{|c|}{ PC5 } \\
\hline & AV.EXC ${ }^{a}$ & $\mathrm{AV} . T_{\max }{ }^{\mathrm{b}}$ & AV.EXC ${ }^{\mathrm{a}}$ & $\mathrm{AV} . T_{\max }{ }^{\mathrm{b}}$ & AV.EXC & $\mathrm{AV} . T_{\text {max }}{ }^{\mathrm{b}}$ & AV.EXC & $\mathrm{AV} . T_{\max }{ }^{\mathrm{b}}$ & AV.EXC ${ }^{\mathrm{a}}$ & $\mathrm{AV} . T_{\text {max }}{ }^{\mathrm{b}}$ \\
\hline & & & & & $2021-2050$ & & & & & \\
\hline KNMI & 5.5 & 1.1 & 0.8 & 0.7 & 5.5 & 1.4 & 2.8 & 0.8 & 1.8 & 0.7 \\
\hline MPI & 4.6 & 0.9 & 0.6 & 0.6 & 4.2 & 1.3 & 2.1 & 0.6 & 1.3 & 0.6 \\
\hline $\mathrm{HC}$ & 12.2 & 2.7 & 1.9 & 1.5 & 10 & 2.6 & 8.0 & 2.0 & 5.7 & 2.5 \\
\hline & & & & & $2071-2100$ & & & & & \\
\hline KNMI & 16.4 & 3.6 & 2.3 & 1.6 & 14.8 & 4.4 & 10.1 & 2.6 & 6.2 & 2.5 \\
\hline MPI & 16.3 & 3.4 & 2.1 & 1.5 & 14.6 & 4.4 & 8.7 & 2.2 & 5.4 & 2.2 \\
\hline $\mathrm{HC}$ & 25.4 & 5.1 & 4.1 & 3.1 & 19.4 & 4.8 & 16.5 & 4.0 & 10.9 & 4.4 \\
\hline
\end{tabular}

${ }^{a}$ Average ozone exceedance days changes (days/yr).

${ }^{\mathrm{b}}$ Average $90^{\text {th }}$ percentile temperature changes $\left({ }^{\circ} \mathrm{C}\right)$. 
(a) E-OBS 90th percentile $\operatorname{Tmax}\left({ }^{\circ} \mathrm{C}\right)$

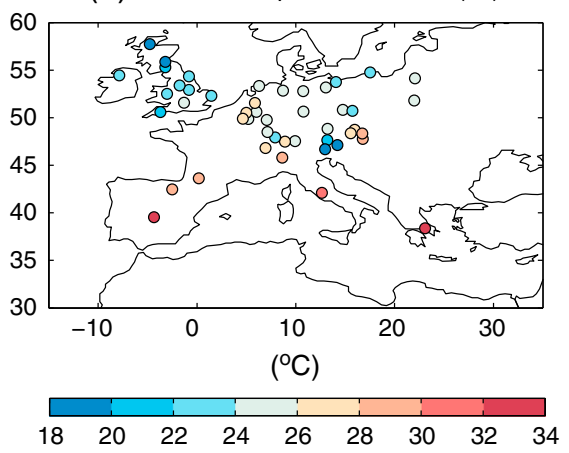

(c) MPI 90th percentile Tmax [2071_2100-E-OBS]

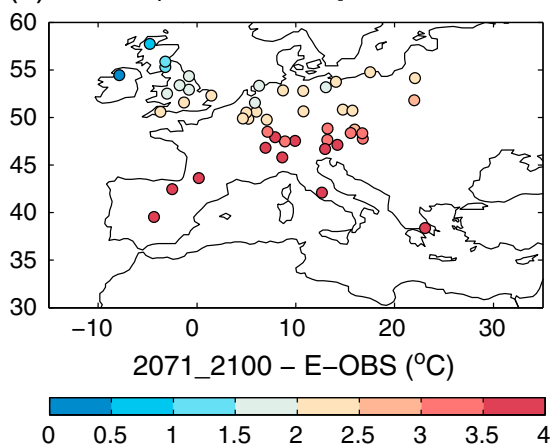

(b) KNMI 90th percentile Tmax [2071_2100 - E-OBS]

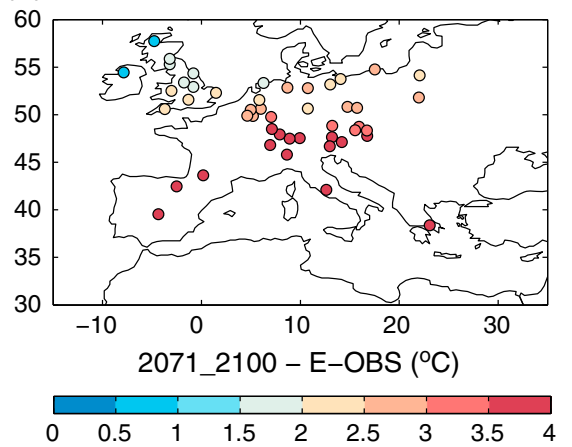

(d) HC 90th percentile Tmax [2071_2100 - E-OBS]

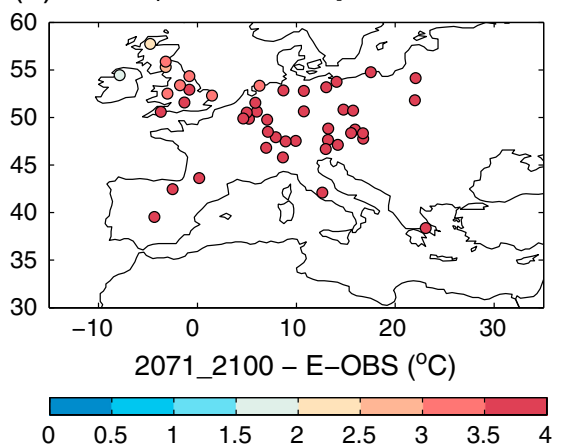

Figure 9. The $90^{\text {th }}$ temperature percentile for the E-OBS for all stations and the differences between the perturbed temperatures of each RCM (KNMI, MPI, HC, Table 2) and the E-OBS for the period 2071-2100. All changes are found statistically significant. For convenience in the comparison with the results of GISS-GEOS/CHEM the same range of values as in Figure 12 has been used.

temperature changes from $\mathrm{HC}$ result in higher changes of ozone exceedances.

[34] Referring to the first future period the highest average changes of ozone exceedances are evident for the stations in PC1 region. For KNMI and MPI the changes are about 5.5 days/yr (relative increase about $13 \%$ with the $95^{\text {th }}$ percentile confidence intervals ranging from 11 to $15 \%$ ) and 4.5 days/yr $(12 \%,(9-14 \%))$ respectively, accompanied by an increase of about $1{ }^{\circ} \mathrm{C}$ (Table 7 ). At this region, the station with the highest increase (about 10.5 days/yr) is found in southern Italy (IT01, Figures $6 \mathrm{~b}$ and $6 \mathrm{c}$ ), accompanied by a temperature increase of about $1.5^{\circ} \mathrm{C}$ (Figures $7 \mathrm{~b}$ and $7 \mathrm{c}$ ). For $\mathrm{HC}$ the average change in $\mathrm{PC} 1$ is higher, reaching 12 days/yr $(30 \%,(26-33 \%))$ and it is accompanied by a temperature increase of about $2.7^{\circ} \mathrm{C}$ (Table 7). Moreover, with this model for 14 stations located mostly in Central and Southern Europe the increases are over 10 days/yr while, the highest one (about 20 days/yr) is found in Austria (AT02, Figures 6d and 7d) and is accompanied by a temperature increase of about $3^{\circ} \mathrm{C}$.

[35] During the second future period, the higher temperature increases (at the $90^{\text {th }}$ percentile, Figure 9) lead to higher increases in the ozone exceedance days (Figure 8). In particular, for KNMI and MPI at 20 and 19 stations, respectively (located mainly in PC1, PC3, and PC4 subregions), more than 10 days/yr additional exceedance days are simulated (Figures $8 \mathrm{~b}$ and $8 \mathrm{c}$ ). These increases are accompanied by temperature increases of more than $2.5^{\circ} \mathrm{C}$ for both models (Figures 9b and 9c). The highest average increase in the ozone exceedances is found at the $\mathrm{PC} 1$ and $\mathrm{PC} 3$ regions reaching $16(40 \%,(33-45 \%))$ and $15(46 \%(29-65 \%))$ extra ozone exceedance days/yr for the two models, respectively. Overall the highest increase is simulated at the AT32 station (PC1) with 28 days/yr (48\%) and 29 days/yr (50\%) for KNMI and MPI, respectively, with a temperature increase around $3.5^{\circ} \mathrm{C}$ for both models (Figures 8b, 9b, and 8c, 9c). For the $\mathrm{HC}$ model, the highest average increase varies from about 16 days/yr in PC4 subregion $(69 \%,(61-76 \%))$ to about 25 days/yr in PC1 $(61 \%,(50-70 \%))$ corresponding to an average increase in temperature varying from about 4 to $5^{\circ} \mathrm{C}$ (Table 7). The highest increase in the ozone exceedance days is also simulated at the AT32 station reaching 42 days/yr (Figure 8d) with a temperature increase of about $5.7^{\circ} \mathrm{C}$ (Figure 9d).

[36] The lowest increases from all models, for both future periods are evident in the northwest subregion (PC2) combined with the lowest temperature increases (Figures 6, 7, 8, and 9 and Table 7). At this region, the average increases, depending on the model, vary from less than a day/yr $(12 \%,(9-15 \%)$ to about 2 days/yr $(39 \%$, $(32-47 \%)$ for the first future period and about 2 days/yr $(39 \%,(30-47 \%))$ to 4 days/yr $(81 \%,(64-98 \%))$ for the second one. It should be noted that our projections of the ozone exceedance days in the northwest subregion should be viewed with caution due to the weaker correlation coefficients between the two variables at the stations identified in this subregion (Table 1). 
(a) Number of ozone exccedance Days

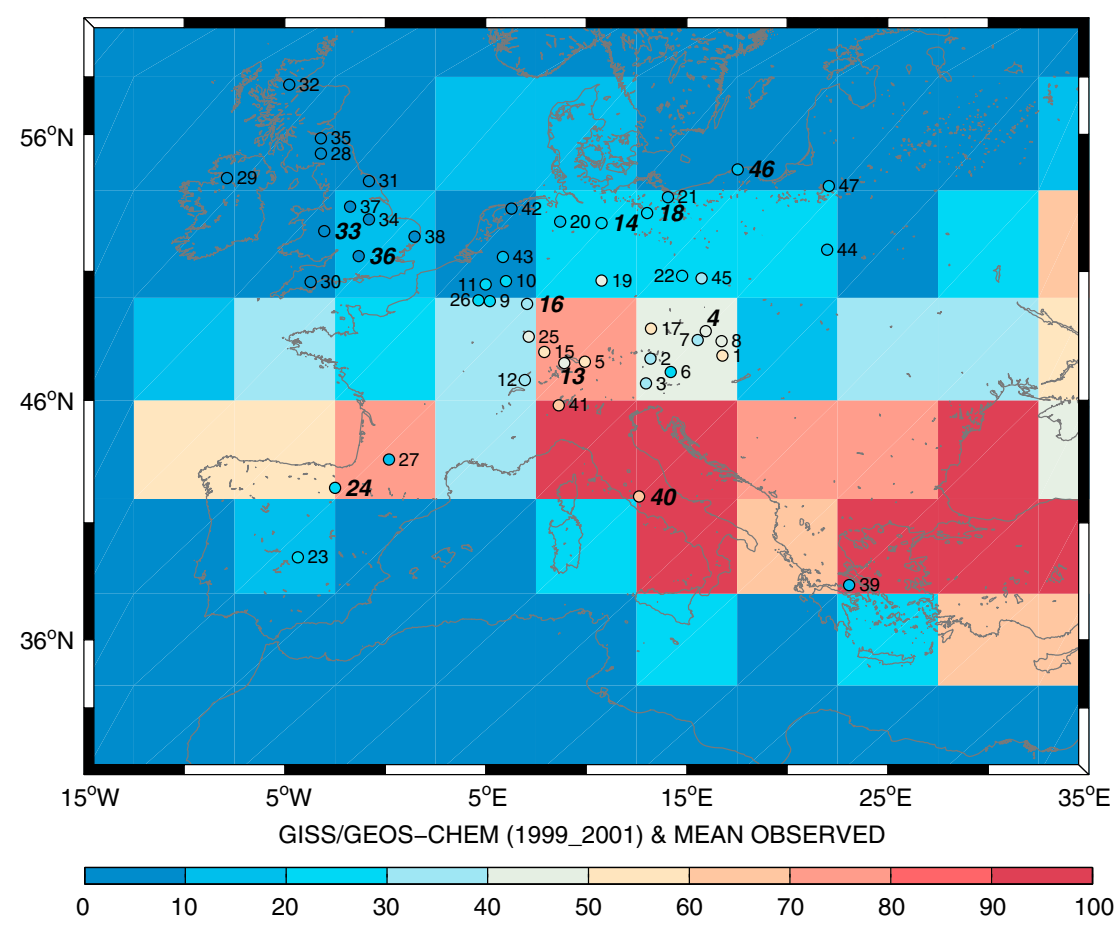

(b) Number of ozone exccedance Days

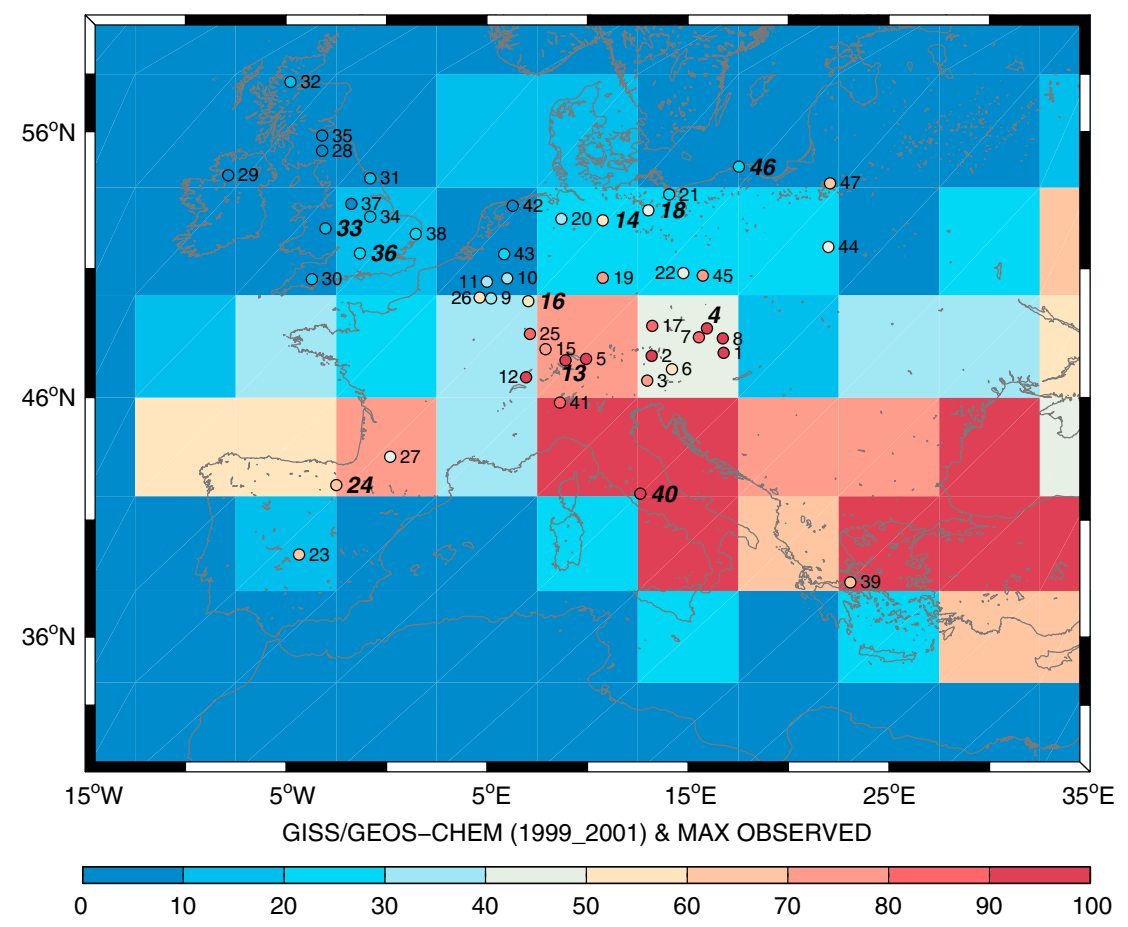

Figure 10. Simulated average ozone exceedances at the lowest model level for the period 1999-2001. Colored circles indicate (a) the average observed values over the years available at each station in Table 1 and (b) the maximum observed values over the years available at each station in Table 1. Subscripts denote station numbers in Table 1.

\subsection{The GISS/GEOS-CHEM Results}

[37] Hourly data from the GISS/GEOS-CHEM chemicaldynamical modeling system for the periods 1999-2001 and
2049-2050 are postprocessed to obtain the daily maximum $8 \mathrm{~h}$ average ozone concentrations and subsequently the ozone exceedance days. It should be noted here that all the results presented in this section are obtained after 


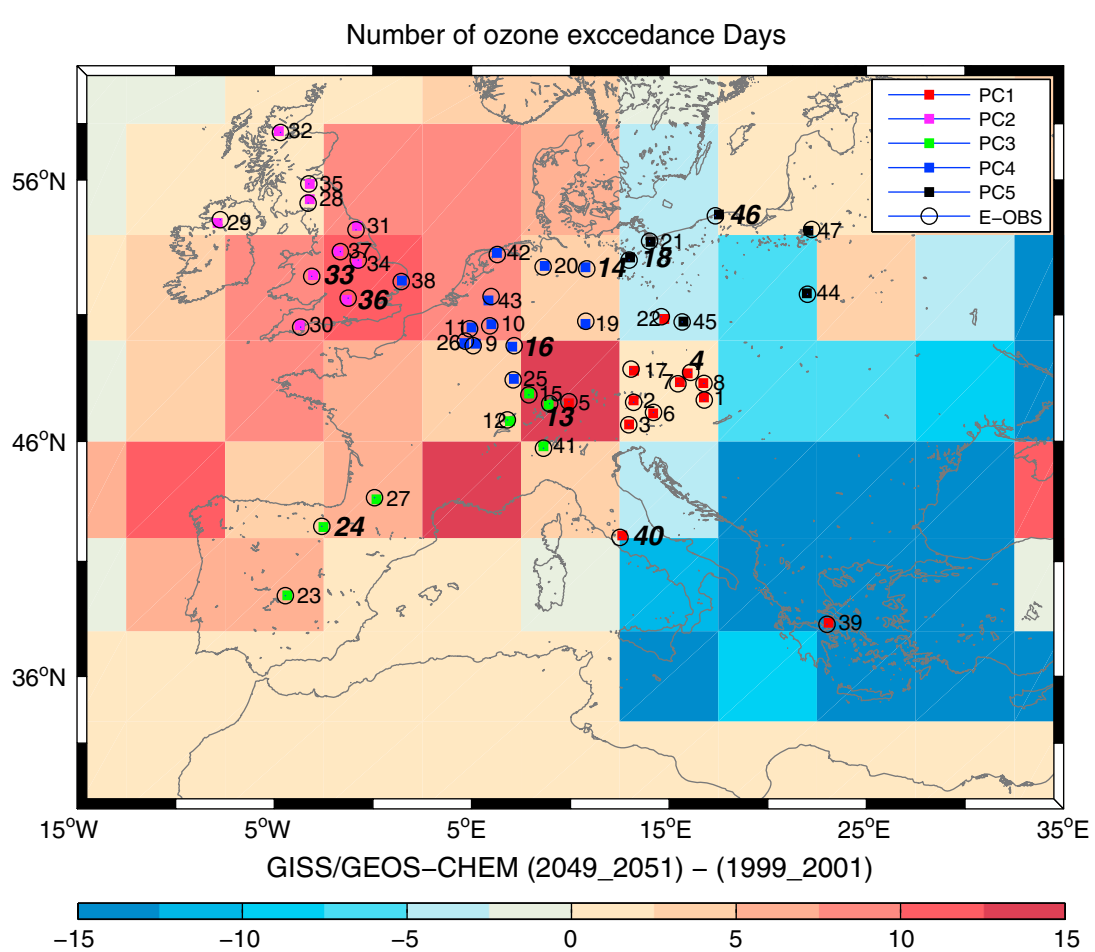

Figure 11. Changes in the average ozone exceedance days within GISS/GEOS-CHEM between the periods 2049-2050 and 1999-2001. For convenience in the comparison with the results for the various stations, Figure 1 has been overplotted. Subscripts denote station numbers in Table 1.

averaging over the two 3 year periods. First, we examine the ability of the GISS/GEOS-CHEM to reproduce the observed ozone exceedances. Then we compare the simulation results with those from the statistical model. As mentioned before, the comparison is not straightforward due to the differences in the horizontal resolution and the time slices used, thus, a more qualitative comparison is presented.

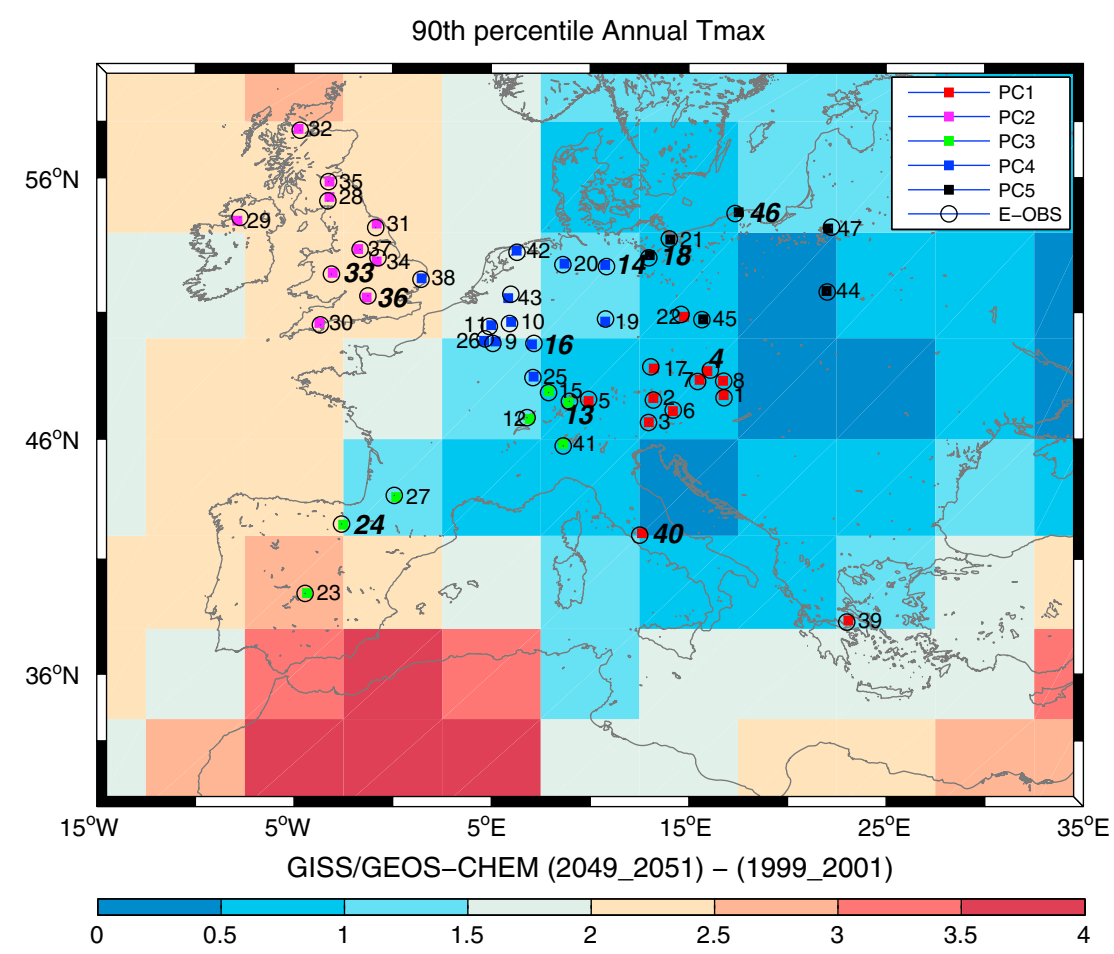

Figure 12. Changes in the average $90^{\text {th }}$ percentile of temperature within GISS/GEOS-CHEM between the periods 2049-2050 and 1999-2001. For convenience in the comparison with the results for the various stations, Figure 1 has been overplotted. Subscripts denote station numbers in Table 1. 
4.6.1. Comparison With the Observed Ozone Exceedances

[38] In Figure 10a the observed ozone exceedances averaged over the years available for each station (Table 1) are shown together with those simulated by the GISS/ GEOS-CHEM for the period 1999-2001. In general, a higher number of ozone exceedance days is simulated by the dynamical model compared to the observations. However, the model seems to be able to reproduce the spatial patterns of ozone exceedances, simulating lower values in the northern areas of the domain and higher in the central and southern Europe. Moreover, the averaged GISS/ GEOS-CHEM simulated ozone exceedances are lower than the annual maximum observed at most of the stations (Figure $10 \mathrm{~b}$ ).

\subsubsection{Comparison With the Statistical Model}

[39] The GISS/GEOS-CHEM results indicate increases in the ozone exceedances in the western and central Europe (Figure 11), similar to the results of the statistical model (Figures 6 and 8). In particular, the maximum increase (about 15 days/yr) is found in central Europe and is between the values simulated from the statistical model for the two future periods for KNMI and MPI (Figures 6b-6c and 8b-8c). Nevertheless, fundamentally different results are shown in eastern Europe (both southern and northern) and in northwest Europe. In particular, unexpected decreases of the number of exceedances are found (Figure 11), despite the temperature increases $\left(90^{\text {th }}\right.$ percentile, Figure 12) in eastern Europe. These decreases are not evident in the results of the statistical model (Figures 6 and 8). On the contrary, the maximum simulated increases in the northwest Europe (area of PC2, Great Britain), are about 10 to 12 days/yr, clearly higher than those estimated by the statistical model. This behavior is evident for all the RCMs and for both future periods. Lower increases are also predicted with the statistical approach at stations of PC3 and PC2 and the majority of the stations of PC1. The combined effect of additional processes driving the changes in ozone concentrations within the dynamical model, have been investigated in a recently published study [Varotsos et al., 2013]. In particular, the authors commented that the increases in the northwest Europe are associated with increased isoprene biogenic emissions due to increased temperatures whereas the decreases in the southeast Europe are associated with the increased wind speeds in the 2050 climate and the increase of water vapor over the marine atmosphere. The decreases in the northeast Europe are attributed to the increased dry deposition due to decreases in snow cover in future climate.

[40] Results from other studies were also considered. For instance, the statistical model's results are comparable to those presented by Forkel and Knoche [2007], with a regional dynamical climate chemistry modeling system. They found an increase in the ozone exceedance days varying from about 2 to 16 extra days in central Europe in the 2030s compared to the 1990s under the IS92a emissions scenario. In addition, Langner et al. [2012] using an ensemble of chemical transport models driven by the ECHAM5 regional climate model under the A1B future emissions scenario, found in most of the models statistically significant increases (between 2050 and 2000) in both the average mean and average daily maximum ozone concentrations in southeastern Europe.

\section{Summary and Conclusions}

[41] We examined the development and application of a statistical model to provide estimates of the impact of climate change on future ozone exceedances based on the fact that the total derivative of ozone with temperature reflects the sum of the partial derivatives of ozone with temperature dependent physical and chemical processes [D.J. Rasmussen et al., 2012] under the assumption that the relationship will retain its main characteristics in the future. Observations of ozone from 47 nonurban stations in Europe with at least 10 years of observations, daily maximum temperatures from the E-OBS gridded data set and temperature simulations from three-state-of-the-art RCMs were implemented in the analysis. A rotated principal components analysis was applied to the ozone concentrations, which led us to delineate five regions of homogeneous concentrations: southeast, southwest, northwest, central-north, and northeast subregions.

[42] During the evaluation period, the discrepancies between the calculated ozone exceedances by the statistical model and the observed ones varied from zero (DE04) to maximum 12 days/yr (25\%) (IT01). To obtain estimates of the future ozone exceedance days under current levels of emissions, the gridded observed daily maximum temperatures were perturbed to deduce the future temperature time series under the A1B Green House Gases emissions scenario using mean monthly differences, calculated from the three RCMs 30 year simulations. Results indicated that average higher increases on the ozone exceedance in terms of days/yr are expected at the stations located at the southeast and southwest subregions, moderate increases are expected for the stations of central north subregion whereas lower increases are expected for the stations in the northwest and northeast subregions for all models and for both future periods. The highest average increases varied from about 5 days/yr (relative change $12 \%$ with $95^{\text {th }}$ percentile confidence range $9-15 \%$ ) to 12 days $/ y r$ (30\%, 25-33\%) for the 2021-2050 period accompanied by increases in the upper extreme of temperature $\left(90^{\text {th }}\right.$ percentile) varying from about $1{ }^{\circ} \mathrm{C}$ to $2.7^{\circ} \mathrm{C}$. The highest average temperature increases for the 2071-2100 period varied from about $3.5^{\circ} \mathrm{C}$ to $5.1^{\circ} \mathrm{C}$ forcing the statistical model to simulate the highest average ozone exceedance days changes in the southeast subregion varying from about 16 days/yr $(35 \%, 33-45 \%)$ to 25 days/yr $(61 \% 50-70 \%)$. On the contrary, the lowest average increases were evident at the stations of the northwest subregion due to the lower temperature changes for all models and for both future periods with the changes, depending on the model, varying from less than a day/yr $(12 \%, 9-15 \%)$ to about 2 days/yr $(39 \%, 32-47 \%)$ for the first future period and about 2 days/yr $(39 \%, 30-47 \%)$ to 4 days/yr $(81 \%, 64-98 \%)$ for the second future period.

[43] A qualitative comparison between the results of the statistical model and the GISS/GEOS-CHEM modeling system was also performed. To this aim, two scenario simulations were performed: (a) present-day climate and anthropogenic emissions and (b) future climate following the IPCC SRES A1B scenario and present-day anthropogenic emissions. The simulations performed here covered two 3 year time slices: 1999-2001 (2000) for the present day climate and 2049-2051 (2050) for future climate. Different results between the two approaches were found only in eastern Europe (both southern and northern) and in northwest 
Europe. In particular, decreases of the number of exceedances were found despite the temperature increases in eastern Europe with these results not being evident in the statistical model. In the northwest Europe (area of PC2, Great Britain), the maximum increases of the ozone exceedance days with the dynamical model is about 10 to 12 days/yr, clearly higher than the results of the statistical model. The contradicting result at this area appears for all the RCMs, for both future periods. Nevertheless, the GISS/GEOS-CHEM results indicated increases in the ozone exceedances at the western and central Europe, similar to the results of the statistical model. In addition, comparison of the statistical models results to the results from other dynamical modeling studies indicated encouraging analogous results for the central and southeast Europe.

[44] The approach presented here is subject to various limitations associated with the basic assumption that the emissions and the relationship of ozone with its precursor emissions will be unchanged in the future. However, the observed ozonetemperature relationship describes the ozone relationship with temperature-dependent physical and chemical processes, which are inherent in the statistical model. Moreover, the results presented here are also dependent on the ability of each RCM to provide realistic projections for the changes in temperature under climate change. Nevertheless, we should also take into account that uncertainties also exist in dynamical models related to differences in chemical and physical parameterization and to input data. We believe that the statistical models can complement the dynamical ones for the estimation of future air quality and could provide tools for policymakers because they are less computationally intensive than the dynamical models. To conclude, results from both statistical and dynamical models could benefit our understanding of climate change impact on air quality.

[45] Acknowledgments. This research has been cofinanced by the European Union (European Social Fund - ESF) and Greek national funds through the Operational Program "Education and Lifelong Learning" of the National Strategic Reference Framework - Research Funding Program: Heracleitus II. Investing in knowledge society through the European Social Fund. The ENSEMBLES and E-OBS data used in this work were obtained the EU FP6 Integrated Project ENSEMBLES (contract GOCE-CT-2003505539) whose support is gratefully acknowledged.

\section{References}

Beniston, M. (2004), The 2003 heat wave in Europe: A shape of things to come? An analysis based on Swiss climatological data and model simulations, Geophys. Res. Lett., 31, 4 PP., doi:200410.1029/2003GL018857.

Bloomer, B. J., J. W. Stehr, C. A. Piety, R. J. Salawitch, and R. R. Dickerson (2009), Observed relationships of ozone air pollution with temperature and emissions, Geophys. Res. Lett., 36, 5 pp., L09803, doi:200910.1029/ 2009GL037308.

Camalier, L., W. Cox, and P. Dolwick (2007), The effects of meteorology on ozone in urban areas and their use in assessing ozone trends, Atmos. Environ., 41(33), 7127-7137, doi:10.1016/j.atmosenv.2007.04.061.

Chang, H. H., J. Zhou, and M. Fuentes (2010), Impact of climate change on ambient ozone level and mortality in Southeastern United States, Int. J. Environ. Res. Public Health, 7(7), 2866-2880, doi:10.3390/ijerph7072866.

Collins, M., B. Booth, G. Harris, J. Murphy, D. Sexton, and M. Webb (2006), Towards quantifying uncertainty in transient climate change, Clim. Dyn., 27(2), 127-147, doi:10.1007/s00382-006-0121-0.

Deque (2007), Frequency of precipitation and temperature extremes over France in an anthropogenic scenario: Model results and statistical correction according to observed values, Global Planet. Change, 57(1-2), 16-26, doi:10.1016/j.gloplacha.2006.11.030.

Diciccio, T. J. (1996), Bootstrap confidence intervals, Statist. Sci., 11(3), 189-228, doi:10.1214/ss/1032280214.

Directive 2008/50/EC of the European Parliament and of the Council of 21 May 2008 on ambient air quality and cleaner air for Europe (2008), (http://eur-
lex.europa.eu/LexUriServ/LexUriServ.do?uri=OJ:L:2008:152:0001:0044: EN:PDF).

Eder, B. K., J. M. Davis, and P. Bloomfield (1993), A characterization of the spatiotemporal variability of non-urban ozone concentrations over the eastern United States, Atmos. Environ. Part A, 27(16), 2645-2668, doi:10.1016/0960-1686(93)90035-W.

Efron, B. (1987), Better Bootstrap Confidence Intervals, J. Am. Stat. Assoc., 82(397), 171-185, doi:10.2307/2289144.

Forkel, R., and R. Knoche (2007), Nested regional climate-chemistry simulations for central Europe, C.R. Geosci., 339(11-12), 734-746, doi:10.1016/j.crte.2007.09.018.

Haylock, M. R., N. Hofstra, A. M. G. Klein Tank, E. J. Klok, P. D. Jones, and M. New (2008), A European daily high-resolution gridded data set of surface temperature and precipitation for 1950-2006, J. Geophys. Res., 113(D20), D20119, doi:10.1029/2008JD010201.

Hedegaard, G. B., J. Brandt, J. H. Christensen, L. M. Frohn, C. Geels, K. M. Hansen, and M. Stendel (2008), Impacts of climate change on air pollution levels in the Northern Hemisphere with special focus on Europe and the Arctic, Atmos. Chem. Phys., 8(12), 3337-3367, doi:10.5194/acp-8-3337-2008.

Hofstra, N., M. Haylock, M. New, and P. D. Jones (2009), Testing E-OBS European high-resolution gridded data set of daily precipitation and surface temperature, J. Geophys. Res., 114, 16 pp., D21101, doi:200910.1029/ 2009JD011799.

Holloway, T., S. N. Spak, D. Barker, M. Bretl, C. Moberg, K. Hayhoe, J. V. Dorn, and D. Wuebbles (2008), Change in ozone air pollution over Chicago associated with global climate change, J. Geophys. Res., 113, 14 pp., D22306, doi:200810.1029/2007JD009775.

Jacob, D. J., and D. Winner (2009), Effect of climate change on air quality, Atmos. Environ., 43(1), 51-63, doi:10.1016/j.atmosenv.2008.09.051.

Jacob, D. (2001), A note to the simulation of the annual and inter-annual variability of the water budget over the Baltic Sea drainage basin, Meteorol. Atmos. Phys., 77(1), 61-73, doi:10.1007/s007030170017.

Jacob, D. J., J. A. Logan, G. M. Gardner, R. M. Yevich, C. M. Spivakovsky, S. C. Wofsy, S. Sillman, and M. J. Prather (1993), Factors regulating ozone over the United States and its export to the global atmosphere, $J$. Geophys. Res., 98(D8), 14817-14826, doi:10.1029/98JD01224.

Jolliffe, I. T. (1993), Principal component analysis: A beginner's guide - II. Pitfalls, myths and extensions, Weather, 48(8), 246-253, doi:10.1002/ j.1477-8696.1993.tb05899.x.

Jonson, J. E., D. Simpson, H. Fagerli, and S. Solberg (2006), Can we explain the trends in European ozone levels?, Atmos. Chem. Phys., 6(1), 51-66, doi:10.5194/acp-6-51-2006.

Kaiser, H. F. (1958), The varimax criterion for analytic rotation in factor analysis, Psychometrika, 23(3), 187-200, doi:10.1007/BF02289233.

Katragkou, E., P. Zanis, I. Kioutsioukis, I. Tegoulias, D. Melas, B. C. Krüger, and E. Coppola (2011), Future climate change impacts on summer surface ozone from regional climate-air quality simulations over Europe, $J$. Geophys. Res., 116, 14 pp., D22307, doi:201110.1029/2011JD015899.

Klein Tank, A. M. G. et al. (2002), Daily dataset of 20th-century surface air temperature and precipitation series for the European Climate Assessment, Int. J. Climatol., 22(12), 1441-1453, doi:10.1002/joc.773.

Klok, E. J., and A. M. G. Klein Tank (2009), Updated and extended European dataset of daily climate observations, Int. J. Climatol., 29(8), 1182-1191, doi:10.1002/joc. 1779 .

Kostopoulou, E., C. Giannakopoulos, M. Hatzaki, and K. Tziotziou (2012), Climate extremes in the NE Mediterranean: Assessing the E-OBS dataset and regional climate simulations, Clim Res, 54(3), 249-270, doi:10.3354/cr01110.

Langner, J., M. Engardt, A. Baklanov, J. H. Christensen, M. Gauss, C. Geels, G. B. Hedegaard (2012), A multi-model study of impacts of climate change on surface ozone in Europe, Atmos. Chem. Phys. Discuss., 12(2), 4901-4939, doi:10.5194/acpd-12-4901-2012.

Langner, J., R. Bergström, and V. Foltescu (2005), Impact of climate change on surface ozone and deposition of sulphur and nitrogen in Europe, Atmos. Environ., 39(6), 1129-1141, doi:10.1016/j.atmosenv.2004.09.082.

Lehman, J., K. Swinton, S. Bortnick, C. Hamilton, E. Baldridge, B. Eder, and B. Cox (2004), Spatio-temporal characterization of tropospheric ozone across the eastern United States, Atmos. Environ., 38(26), 4357-4369, doi:10.1016/j.atmosenv.2004.03.069.

Leibensperger, E. M., L. J. Mickley, and D. J. Jacob (2008), Sensitivity of US air quality to mid-latitude cyclone frequency and implications of 1980-2006 climate change, Atmos. Chem. Phys., 8(23), 7075-7086, doi:10.5194/acp-8-7075-2008.

Lin, C.-Y. C., D. J. Jacob, and A. M. Fiore (2001), Trends in exceedances of the ozone air quality standard in the continental United States, 1980-1998, Atmos. Environ., 35(19), 3217-3228, doi:10.1016/ S1352-2310(01)00152-2.

McCluskey, A., and A. G. Lalkhen (2007), Statistics IV: Interpreting the results of statistical tests, Contin Educ Anaesth Crit Care Pain, 7(6), 208-212, doi:10.1093/bjaceaccp/mkm042. 


\section{VAROTSOS ET AL.: CLIMATE CHANGE AND AIR-QUALITY}

Meleux, F., F. Solmon, and F. Giorgi (2007), Increase in summer European ozone amounts due to climate change, Atmos. Environ., 41(35), 7577-7587, doi:10.1016/j.atmosenv.2007.05.048.

Millán, M. M., M. J. Sanz, R. Salvador, and E. Mantilla (2002), Atmospheric dynamics and ozone cycles related to nitrogen deposition in the western Mediterranean, Environ. Pollut., 118(2), 167-186.

Mudelsee, M., and M. Alkio (2007), Quantifying effects in two-sample environmental experiments using bootstrap confidence intervals, Environ. Modell. Softw., 22(1), 84-96, doi:10.1016/j.envsoft.2005.12.001.

Nakicenovic N. and R. Swart (2000), Special Report on Emissions Scenarios. A Special Report of Working Group III of the Intergovernmental Panel on Climate Change, 570 pp., Cambridge University 661 Press: Cambridge, UK and New York.

Ordóñez, C., H. Mathis, M. Furger, S. Henne, C. Hüglin, J. Staehelin, and A. S. H. Prévôt (2005), Changes of daily surface ozone maxima in Switzerland in all seasons from 1992 to 2002 and discussion of summer 2003, Atmos. Chem. Phys., 5(5), 1187-1203, doi:10.5194/acp-5-1187-2005.

Protonotariou, A. P., M. Tombrou, C. Giannakopoulos, E. Kostopoulou, and P. Le Sager (2010), Study of CO surface pollution in Europe based on observations and nested-grid applications of GEOS-CHEM global chemical transport model, Tellus B, 62(4), 209-227, doi:10.1111/j.1600-0889.2010.00462.

Rasmussen, D. J., A. M. Fiore, V. Naik, L. W. Horowitz, S. J. McGinnis, and M. G. Schultz (2012), Surface ozone-temperature relationships in the eastern US: A monthly climatology for evaluating chemistry-climate models, Atmos. Environ., 47(0), 142-153, doi:10.1016/j.atmosenv.2011.11.021.

Rasmussen, J., T. O. Sonnenborg, S. Stisen, L. P. Seaby, B. S. B. Christensen, and K. Hinsby (2012), Climate change effects on irrigation demands and minimum stream discharge: Impact of bias-correction method, Hydrol. Earth Syst. Sci., 16(12), 4675-4691, doi:10.5194/hess-16-4675-2012.

Rind, D., J. Lerner, J. Jonas, and C. McLinden (2007), Effects of resolution and model physics on tracer transports in the NASA Goddard Institute for Space Studies general circulation models, J. Geophys. Res., 112(D9), D09315, doi:10.1029/2006JD007476.

Schär, C., P. L. Vidale, D. Luthi, C. Frei, C. Haberli, M. A. Liniger, and C. Appenzeller (2004), The role of increasing temperature variability in European summer heatwaves, Nature, 427(6972), 332-336, doi:10.1038/ nature 02300

Sillman, S. (1999), The relation between ozone, NOx and hydrocarbons in urban and polluted rural environments, Atmos. Environ., 33(12), 1821-1845, doi:10.1016/S1352-2310(98)00345-8.

Sillman, S., and P. J. Samson (1995), Impact of temperature on oxidant photochemistry in urban, polluted rural and remote environments, J. Geophys. Res., 100(D6), 11497-11508, doi:10.1029/94JD02146.
Steiner, A. L., A. J. Davis, S. Sillman, R. C. Owen, A. M. Michalak, and A. M. Fiore (2010), Observed suppression of ozone formation at extremely high temperatures due to chemical and biophysical feedbacks, Proceedings of the National Academy of Sciences, doi:10.1073/ pnas. 1008336107.

Van Meijgaard, E., L. H. van Ulft, W. J. van de Berg, F. C. Bosveld, B. J. J. M. van den Hurk, G. Lenderink, and A.P. Siebesma (2008), The KNMI regional atmospheric climate model RACMO, ver-sion 2.1 , KNMI Technical Report TR-302, available from KNMI, P.O. Box 201, NL-3730 AE De Bilt, The Netherlands, 43 pp.

Varotsos, K. V., C. Giannakopoulos, and M. Tombrou (2013), Assessment of the Impacts of climate change on European ozone levels, Water Air Soil Pollut., 224(6), 1-13, doi:10.1007/s11270-013-1596-Z.

Vautard, R., M. Schaap, R. Bergström, B. Bessagnet, J. Brandt, P. J. H. Builtjes, J. H. Christensen (2009), Skill and uncertainty of a regional air quality model ensemble, Atmos. Environ., 43(31), 4822-4832, doi:10.1016/j.atmosenv.2008.09.083.

Vautard, R., C. Honoré, M. Beekmann, and L. Rouil (2005), Simulation of ozone during the August 2003 heat wave and emission control scenarios, Atmos. Environ., 39(16), 2957-2967, doi:10.1016/j.atmosenv.2005.01.039.

Weaver, C. P. et al. (2009), A Preliminary Synthesis of Modeled Climate Change Impacts on U.S. Regional Ozone Concentrations, Bulletin of the American Meteorological Society, 90(12), 1843-1863, doi:10.1175/ 2009BAMS2568.1.

Wilks, D. S. (2011), Statistical Methods in the Atmospheric Sciences, Academic Press.

Wise, E. K. (2009), Climate-based sensitivity of air quality to climate change scenarios for the southwestern United States, Int. J. Climatol., 29(1) 87-97, doi:10.1002/joc. 1713.

Wise, E., and A. Comrie (2005), Meteorologically adjusted urban air quality trends in the Southwestern United States, Atmos. Environ., 39(16), 2969-2980, doi:10.1016/j.atmosenv.2005.01.024.

Wu, S., L. J. Mickley, D. J. Jacob, D. Rind, and D. G. Streets (2008), Effects of 2000-2050 changes in climate and emissions on global tropospheric ozone and the policy-relevant background surface ozone in the United States, J. Geophys. Res., 113(D18), D18312, doi:10.1029/2007JD009639.

Yu, T.-Y., and L.-F. W. Chang (2000), Selection of the scenarios of ozone pollution at southern Taiwan area utilizing principal component analysis, Atmos. Environ., 34(26), 4499-4509, doi:10.1016/S1352-2310(00)00112-6.

Zheng, J. Swall, W. Cox, and J. Davis (2007), Interannual variation in meteorologically adjusted ozone levels in the eastern United States: A comparison of two approaches, Atmos. Environ., 41(4), 705-716, doi:10.1016/j. atmosenv.2006.09.010 